\title{
Lead time aggregation: A three-echelon supply chain model
}

Jafar Heydari ${ }^{1}$, Mansour Mahmoodi ${ }^{2}$, Ata Allah Taleizadeh ${ }^{1}$

${ }^{1}$ School of Industrial Engineering, College of Engineering, University of Tehran, Iran

2 Department of Industrial Engineering, Farabi Campus, University of Tehran, Iran

\section{Jafar Heydari (corresponding Author)}

E-mail: J.Heydari@ut.ac.ir

Tel: +982182084489 


\title{
Lead time aggregation: A three-echelon supply chain model
}

\begin{abstract}
In this paper, destructive effects of upstream aggregated stochastic lead times on the supply chain (SC) performance are analyzed. For this purpose, a three-echelon SC consisting of one producer, one distributor, and one retailer is modeled. Both the producer and distributor face stochastic lead times, which can be also aggregated to create a long unpredictable lead time. In order to scale down shortages at the retailer site, an incentive scheme is proposed to convince the upstream members to increase their reorder points. Applying the coordinated model considerably increases the total profit earned by the whole SC as well as all SC members.
\end{abstract}

Keywords: Supply chain coordination; lead time aggregation; stochastic lead time; threeechelon supply chain

\section{Introduction}

Supply chain is a system in which all participants cooperate to make a product and deliver it to end customers. Steady flow of materials is a key factor to create an integrated supply chain. The goal of all SC members is to provide a product/service for customers and in turn gain profit from the customers. To achieve this goal, coordination between SC members is required. Supply chain decision structures can be divided into three types based on the relationship between members, namely decentralized, centralized, and coordinated decision making models. Under the decentralized model, each member decides according to its own profit function, while in the centralized model, decisions are made based on the overall SC goal. However, applying the centralized model is often impossible from the practical point of view, because it is disadvantageous for some members (Heydari, 2014b). So, there is a need for an incentive mechanism to entice SC members to shift from the decentralized model to the centralized one (Govindan et al., 2013). In other words, all SC members need enough incentives to be committed to the jointly agreed decisions, which is called coordinated decision making. Meanwhile, lead time can affect the flow of materials throughout the supply chain and reduce the overall SC performance.

Lead time is the duration between placing an order and receiving it. This duration is due to production, transportation, batch processing, etc., which may be long and stochastic. Long and stochastic lead times can interrupt the production process and inventory planning and also decrease service level (Louly and Dolgui, 2013). In real cases, a supply chain may encounter long and stochastic lead times because of the competitive condition of today's global trades (Blackburn, 2012). Change in production process, transportation, and inspection procedures leads to fluctuations in lead times and, consequently, unexpected shortages/surplus in inventory systems (Sajadieh et al., 2009).

The discussed lead time issue is critical in most companies, because the long and uncertain lead times may lead to many disruptions in SC performance. For example, JAM Electronics that is a 
Korean manufacturer with five facilities in different countries stores the finished products in a central warehouse in Korea and ships them from to different distributors or final customers. In the late 90s and early 2000s, the company's service level in the USA market was constantly low and about $30 \%$ of the orders were not delivered on time. The major reason for the low service level was long lead time within the supply chain. There were two primary reasons for the long lead time: first, long processing time in the central distribution center and, second, very long transits (Simchi-Levi et al., 2000). In another case, in 2014, Nepal's domestic footwear industry was confronted with raw material shortage due to the halt of raw material imports from Chinese suppliers which were in contract for supplying $40 \%$ of the required raw materials. As a result, some small factories were closed down and some confronted lost sales due to supply disruption and supply uncertainty (Kathmandu Post, 2014). There are many real instances of long and uncertain lead times that make downstream members and SC service level inefficient. For example, in 1997, Boeng Company faced a write-down of 2.6 billion dollars which was caused in part from part-suppliers shortages. In 1999, Apple Company could not respond to the customers' demand due to the late supply of G4 chips supplied by Motorola Company. Another evidence of the investigated issue in this study is Okuma America Corporation, a machine tool builder. Okuma requires each of its 46 distributors to carry a minimum inventory to ensure there is enough inventory at all times either in its warehouse or somewhere in the distribution channel. Using this strategy, Okuma prevents shortages due to long and uncertain supply lead time (Narus and Anderson, 1996). Similar to the case of Okuma, in this study, we propose a model to ensure enough inventories in both producer and distributor centers while avoiding the propagation of undesirable effects of supply lead time uncertainties.

Lead time aggregation means crossing an SC member's lead time with some or all of the upstream members' lead times. In other words, the aggregation of lead times may occur when the upstream is out of stock at time of issuing an order by the downstream. In the case of lead time aggregation, the downstream member faces an unpredictable long lead time, which in turn causes large shortages.

In this paper, a three-echelon supply chain is investigated in which both the producer and distributor are confronted with stochastic lead times. The retailer plans a reasonable service level based on the received demand and its fixed lead time. However, in some replenishment cycles, where all members concurrently replenish their stock, lead time aggregation may occur, which in turn causes substantial lowering in the service level. Our investigation revealed that the major reason for these situations is lead time aggregation of two successive or whole supply chain members. According to the definition of lead time aggregation, if upstream is out of stock at the time of issuing an order by downstream, then lead times are aggregated. Accordingly, if the upstream replenishes its stock earlier by setting its reorder point in a higher position; then, the possibility of lead time aggregation diminishes. Lead time aggregation occurs due to supply uncertainty or unreliable supply system. Avoiding lead time aggregation reduces shortage occasions and, therefore, increases SC service level as well as SC profitability. However, shifting reorder point to a higher position leads to more surplus inventory for upstream members; 
therefore, they refuse to do so and do not participate in this scheme unless their benefits are guaranteed.

Questions that will be answered during this study are: (1) is it possible to create a replenishment policy for upstream members in order to reducing risk of lead time aggregation? (2) What are the optimal replenishment policies consisting of reorder point and order quantity decisions for SC upstream members in presence of lead time aggregation? (3) How can an appropriate incentive mechanism be proposed to induce upstream members to accept these optimal policies? To answer these questions, a three-echelon supply chain model with one producer, one distributor, and one retailer is modeled. When the inventory level at the retailer site reaches the reorder point level, an order is placed to the distributor; if the distributor has enough inventories, then after a fixed lead time, the issued order will be delivered. Similarly, at the distributor site when the inventory level reaches the distributor's reorder point, an order will be sent to the producer that will be delivered after a stochastic lead time with the known mean and variance. Also, the producer orders from an external supplier with a stochastic lead time. If lead time aggregation happens at the retailer site, then shortages occur. It is assumed that shortages will be backordered with a penalty cost at the retailer site. While the retailer faces shortage costs, the upstream members will never incur shortage costs due to their higher bargaining power. Supply chain is modeled under two different settings: (1) Decentralized decision making model in which each SC member decides based on its own profit and (2) Centralized decision making model in which all SC members collaborate to increase the overall SC profitability. Under the decentralized decision making, upstream members may choose a lower reorder point to decrease their inventory holding costs. However, under centralized decision making model, to reduce shortage costs, it is expected from upstream members to raise their reorder points to prevent costly shortages at the retailer site. Therefore, in the centralized model, upstream inventory holding costs will increase, so there is a need for an incentive scheme to compensate for the increased costs of the upstream members. Such an incentive scheme guarantees the participation of all SC members in the joint decision making. A company may apply two kinds of strategies, namely adapter and shaper strategies, when confronting uncertainties. In the adapter strategy, the company does not focus on uncertainty levels, but controls the company's own operations and planning processes to adapt to the uncertainties such as increasing inventory levels and keeping more safety stocks. In contrast, by applying a shaper strategy, company tries to form uncertainties in a desired shape. Shaper strategies let the company adjust the risk of uncertainties (Gupta and Maranas, 2006). In this study, a strategy is applied which is shaper from the retailer's perspective and, at the same time, is considered an adapter strategy from the whole SC viewpoint; we can call the proposed strategy a semi-shaper strategy. Based on the proposed strategy, upstream members raise their reorder points in order to decrease the likelihood of lead time aggregation.

In the proposed model, the optimum inventory control policy in a three-echelon supply chain is extracted in light of stochastic lead time between upstream members by considering the 
probability of crossing these stochastic lead times. In addition, the proposed model includes an applicable scheme to induce upstream members to accept the optimal policy.

The contribution of this paper can be considered from two main aspects: first, in terms of the mathematical model as well as structure and concept of lead time aggregation. Accordingly, the effect of lead time aggregation phenomenon in a three-echelon SC is investigated and a threelayer SC decision structure is modeled by considering stochastic lead times for upstream members which can be aggregated. Second, in terms of using a semi-shaper strategy to deal with uncertainties in a way that downstream is not restricted to use an adapter strategy. Applying adapter strategies against demand or lead time uncertainties is common in most of the previous research, while in this study, we propose a semi-shaper strategy in order to deal with uncertainties. In the proposed model, instead of adjusting its own replenishment policy as an adapter strategy, the downstream tries to reduce the risk of lead time aggregation by motivating the upstream members to adjusting their replenishment policy.

The rest of this paper is organized as follows. Section 2 contains the literature review and Section 3 includes supply chain modeling under three different decision structures, i.e. decentralized, centralized, and coordinated models. Section 4 presents numerical experiments and, finally, Section 5 concludes the paper and discusses future research directions.

\section{Literature review}

This paper is focused on minimizing SC costs by optimizing replenishment policy and coordinating the SC members' decisions. Supply chain includes all the activities related to the flow of materials from supply centers to final consumers. Creating an efficient flow of goods throughout the entire supply chain with minimum costs and acceptable service level requires a set of plans that falls into a form of SC management (Simchi-Levi et al., 2004). Meanwhile, the issue of long and also unpredictable lead times affects SC members' efficiency and makes supply chain management more complicated.

Lead time is an inherent part of any production/transportation system which is defined as "the duration between issuing and delivering an order by one SC member" (Heydari 2014a). Generally, lead times will fluctuate for various reasons such as business-environment complexities and these fluctuations will cause some disadvantages for all SC participants. Reduction of lead time uncertainty can decrease downstream inventory costs. Based on lead time definition, many companies have used the lead time control strategies to create a competitive advantage by reducing their safety stock level and shortages occasions at the same time (Hsu and Lee, 2009). Lead time management causes a substantial increase in SC profit, especially when the certainty assumption of lead time is relaxed. To create a more accurate model of the real world, lead time should be modeled as an uncertain element. In Sarker and Coate (1997), a competition based on the set up cost reduction was intended to reduce setup time and improve SC responding in the variable lead time environment with finite investment. In the model proposed by Pan and Hsiao (2001), negotiable backorder ratio was calculated proportionate to the price discount offered by the supplier and also the lead time reduction costs were considered 
in the proposed model. In the study by Arkan and Hejazi (2012), a supply chain model under the assumption of stochastic demand was studied in which lead time duration and ordering costs could be decreased by paying a more amount. A continuous inventory review model with controllable lead times introduced by Priyan and Uthayakumar (2015) resulted in optimal solutions under the uncertainty of the received quantities. The importance and effect of lead time on the management of supply chain in today's competitive business environments were investigated by Blackburn (2012). Bischak et al. (2014) proposed a periodic inventory review model considering stochastic demand and stochastic lead time and order crossovers and then the effects of fluctuations of lead time with gamma distribution on the inventory costs were investigated. With respect to the nature of lead time, it was inferred that normal distribution for lead times would be appropriate for two-echelon inventory models (Hoque, 2013b). Fang et al. (2013) developed a continuous inventory review system with both demand and supply variability. By utilizing a simulation analysis, they showed that reducing lead time mean and variance did not guarantee more surpluses under all the circumstances. Mason et al. (2003) showed both warehouse management systems and transportation management systems as the key factors to integrate the products flow into the supply chain; it was demonstrated that this integrated system could lead to customer service improvement, costs reduction, and lead time variation reductions. Lead time could impress the SC members' decisions and its shortening would improve SC performance. On this basis, in order to minimize total costs, Pan and Yang (2002) and Pan and Hsiao (2005) have optimized the lead time by considering a model with controllable lead times. Gong and Yucesan (2012) incorporated the issue of non-zero lead times into the multi-location transshipment problem. They solved transshipment problems with nonnegligible replenishment lead times and a stochastic demand points.

Generally, according to most of the supply chain models, it can be revealed that upstream performance is more important than the downstream one, because it affects SC efficiency more deeply (Kim and Glock, 2013). Lead time is one of the most effective parameters for SC performance which is mainly influenced by upstream members. Demand and lead time uncertainties could substantially affect the SC performance. Simultaneous occurrence of these two issues, i.e. demand and lead time uncertainty, creates highly uncertain lead time demand which can affect SC performance (Heydari et al., 2009). Lead time uncertainty along with a constrained customer service level was examined by Li et al. (2011). Lead time fluctuations caused dissatisfaction among all SC members, so each member was forced to be adapted to the implied uncertainties. In this way, Ben-Daya and Hariga (2004) investigated a single-vendor single-buyer inventory model with stochastic demand and variable lot-size-dependent lead time. In this model, lead time was composed of two parts: (1) lot size-dependent run time and (2) constant delay times.

Recently, the issue of SC integrated replenishment decision has been highly regarded. This topic is also related to the current study. In the model by Lee and $\mathrm{Fu}$ (2014), a joint production and delivery quantity model in a producer-buyer SC was investigated considering a single-setup multi-delivery setting, which took into account the key role of transportation cost in managing a 
real-life supply chain. It was shown that their proposed optimization model caused a considerable reduction on SC costs. Hsu and Lee (2009) developed an integrated manufacturerretailer chain and perused the effect of upstream shortages level in terms of formulating replenishment decisions.

However, all the previous studies have shown that reduced lead time is a useful strategy, but would not be possible in all situations, like when there is very long distance between supply and demand centers in an SC. Therefore, lead time could not be reduced as expected on all occasions (Heydari, 2014a). In such cases, the coordination of the whole SC will be more effective. Coordinating the relationship between SC members is achieved through contracts. In a supply chain contract, decisions such as order quantity, timings, price, etc. are made jointly. The main purpose of a contract is to agree on how to share risks and profits and how to gain maximum profits for the whole SC (Arshinder, 2008).

Coordinating and managing the integrated inventory model of the supply chain with the assumption of deterministic lead times has been considered in many of the previous studies, while changes in production processes as well as controlling, loading, transporting, and unloading goods may cause fluctuations in lead times (Sajadieh et al., 2009). To overcome deficiencies caused by uncertain lead times, SC members should be coordinated in the presence of stochastic lead times in order to integrate the supply chain (Sarmah et al., 2006; Tarantilis, 2008). Following this issue, coordination of production flow in a two-echelon supply chain with normally distributed lead time and a constraint on fulfilling demand was taken into account by Hoque (2013a). In another work, Nobless et al. (2014) investigated the influence of batch size decisions on lead time in a production-inventory system with limited capacity. The optimal replenishment cycle in a multi-period production-inventory system with non-stationary stochastic demand and lead time was extracted in the presence of service level constraint (Rosii et al., 2010). The results indicated that lead time fluctuations could greatly affect the system parameters. Integration between SC members prevents time delays between two successive SC members such as information delay, ordering delay, transshipment delay, etc. (Louly and Dolgui, 2013). Heydari (2014b), by reducing lead time fluctuations as an incentive scheme, proposed a coordination model to convince the retailer to accept the optimal decision. In the study by Heydari (2014a), the influence of the aggregation of both the supplier and retailer stochastic lead times in a two-echelon supply chain was investigated. In the mentioned study, cost function of each member was extracted and solved in terms of uncertain lead times and, finally, a coordination mechanism was presented to persuade the supplier to participate in the optimization process. Clearly, the lack of coordination between independent members in an SC led to poor performance.

Table 1 illustrates the differences between previous related works and the current study. Regarding the reviewed literature and also Table 1, most of the previous studies have used twoechelon supply chain structure and an adapter strategy (e.g. holding safety stock) to confront lead time uncertainties. 
Table1. Comparing previous related works

\begin{tabular}{|c|c|c|c|c|c|c|c|c|}
\hline \multirow{2}{*}{ Study } & \multicolumn{2}{|c|}{ Model structure } & \multicolumn{2}{|c|}{ Inv. review system } & \multicolumn{2}{|c|}{ Shortages } & \multirow{2}{*}{ Stochastic variables } & \multirow{2}{*}{ Decision variables } \\
\hline & \begin{tabular}{c|c} 
Two- \\
echelon
\end{tabular} & $\begin{array}{c}\text { Multi- } \\
\text { echelon }\end{array}$ & 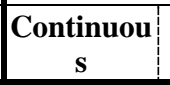 & Periodic & \begin{tabular}{l|l} 
Back \\
order
\end{tabular} & $\begin{array}{l}\text { Lost } \\
\text { sale }\end{array}$ & & \\
\hline \multirow{2}{*}{$\begin{array}{l}\text { Pan and } \\
\text { Hsiao } \\
\text { (2001) }\end{array}$} & $*$ & & $*$ & & $*$ & & Demand: Normal distribution & $\begin{array}{l}\text { Order quantity, Back-order price } \\
\text { discount, Lead time }\end{array}$ \\
\hline & \multicolumn{8}{|c|}{$\begin{array}{l}\text { Issue: An inventory model with negotiable backorders between a supplier and a buyer is developed. The supplier offers } \\
\text { discounts for backordered items. The model is further extended to include the case of negotiable lead times. }\end{array}$} \\
\hline \multirow{2}{*}{$\begin{array}{l}\text { Hsu and Lee } \\
\qquad(2009)\end{array}$} & \begin{tabular}{c|} 
Multiple- \\
retailer
\end{tabular} & & & $*$ & $*$ & & Demand: Distribution-free & $\begin{array}{l}\text { Lead time, Common shipment cycle } \\
\text { time, Target level of replenishments, } \\
\text { Number of shipments }\end{array}$ \\
\hline & \multicolumn{8}{|c|}{$\begin{array}{l}\text { Issue: An integrated inventory system considering the effect of the manufacturer's shortage level is developed. A more } \\
\text { general model based on the minimax distribution free procedure is proposed to simultaneously determine the decision } \\
\text { variables. }\end{array}$} \\
\hline \multirow{2}{*}{$\begin{array}{l}\text { Li et al. } \\
\text { (2011) }\end{array}$} & $*$ & & $*$ & & $*$ & & Demand: Normal distribution & $\begin{array}{c}\text { Order quantity, Lead time, Number of } \\
\text { vendor shipments, Ratio of price } \\
\text { discount }\end{array}$ \\
\hline & \multicolumn{8}{|c|}{$\begin{array}{l}\text { Issue: Inventory models of decentralized and centralized SCs with controllable lead time and service level constraint are } \\
\text { optimized. A coordination mechanism to achieve centralized model is proposed. }\end{array}$} \\
\hline \multirow[b]{2}{*}{$\begin{array}{l}\text { Hoque } \\
\text { (2013) }\end{array}$} & $*$ & & $*$ & & $*$ & & Lead time: Normal distribution & $\begin{array}{l}\text { Order quantity, Reorder point, } \\
\text { Number of shipments }\end{array}$ \\
\hline & \multicolumn{8}{|c|}{$\begin{array}{l}\text { Issue: A minimal total cost solution technique to an integrated vendor-buyer model considering set up time, loading, } \\
\text { unloading, inspection, and transportation time of a batch is presented. The model considers some constraints such as } \\
\text { transportation capacity. }\end{array}$} \\
\hline \multirow{2}{*}{$\begin{array}{c}\text { Noblesse et al. } \\
\qquad(2014)\end{array}$} & * & & * & & $*$ & & $\begin{array}{l}\text { Demand: Compound Poisson } \\
\text { distribution } \\
\text { Lead time: Determined by the } \\
\text { inventory model }\end{array}$ & Reorder point, Order-up-to level \\
\hline & \multicolumn{8}{|c|}{$\begin{array}{l}\text { Issue: The lot sizing decision in a production/inventory setting is proposed to minimize the expected ordering and inventory } \\
\text { related costs over time by developing a procedure to obtain the distribution of lead times and inventory levels. }\end{array}$} \\
\hline \multirow[t]{2}{*}{$\begin{array}{l}\text { Heydari } \\
(2014 a)\end{array}$} & $*$ & & $*$ & & * & & $\begin{array}{l}\text { Retailer lead time: Normal } \\
\text { distribution } \\
\text { Supplier lead time: Normal } \\
\text { distribution }\end{array}$ & $\begin{array}{l}\text { Ordering multiplier of the supplier } \\
\text { and the retailer, supplier's reorder } \\
\text { point factor }\end{array}$ \\
\hline & \multicolumn{8}{|c|}{$\begin{array}{l}\text { Issue: Effects of aggregated lead times of the upstream and downstream members on a two-echelon SC are optimized. An } \\
\text { effective incentive scheme to coordinate the SC is developed. }\end{array}$} \\
\hline \multirow{2}{*}{$\begin{array}{l}\text { Heydari } \\
\text { (2014b) }\end{array}$} & $*$ & & $*$ & & & $*$ & $\begin{array}{l}\text { Lead time: Normal distribution } \\
\text { Demand: Normal distribution }\end{array}$ & $\begin{array}{l}\text { Customer Service level, Lead time } \\
\text { variance }\end{array}$ \\
\hline & \multicolumn{8}{|c|}{$\begin{array}{l}\text { Issue: Service level coordination in a two-echelon SC is investigated. Lead time variability reduction is used as an incentive } \\
\text { scheme to convince downstream to participate in the plan. The model is further extended to include the case of demand } \\
\text { uncertainty. }\end{array}$} \\
\hline \multirow{2}{*}{$\begin{array}{l}\text { Priyan and } \\
\text { Uthayakumar } \\
\qquad(2015)\end{array}$} & $*$ & & $*$ & & * & $*$ & $\begin{array}{l}\text { Demand: Normal distribution } \\
\text { Supply: Normal distribution }\end{array}$ & $\begin{array}{l}\text { Lead time, Ordering cost, Order } \\
\text { quantity, Fraction of the demand } \\
\text { backordered }\end{array}$ \\
\hline & \multicolumn{8}{|c|}{$\begin{array}{l}\text { Issue: Total SC cost is minimized by simultaneously optimizing lead time, lost sales rate, and order processing cost. Leac } \\
\text { time crashing cost is considered an exponential function of lead time. }\end{array}$} \\
\hline \multirow{2}{*}{ Current study } & & $\begin{array}{l}\text { Three- } \\
\text { echelon }\end{array}$ & $*$ & & $*$ & & $\begin{array}{l}\text { Distributor lead time: Normal } \\
\text { distribution } \\
\text { Producer lead time: Normal } \\
\text { distribution }\end{array}$ & $\begin{array}{l}\text { Reorder points coefficients, Ordering } \\
\text { multipliers of the distributor and the } \\
\text { producer }\end{array}$ \\
\hline & \multicolumn{8}{|c|}{$\begin{array}{l}\text { Issue: A three-echelon SC with stochastic lead times is investigated for upstream members by considering the possibility of } \\
\text { lead time aggregation. SC members' replenishment decisions are coordinated using a semi-shaper strategy through } \\
\text { convincing upstream members to enhance their reorder points. }\end{array}$} \\
\hline
\end{tabular}


In this study, a concept namely lead time aggregation is defined and disruptive effects of stochastic lead time aggregation on SC costs using an analytical approach are investigated. The models are proposed in a three-echelon SC structure when both the producer and distributer face stochastic lead times.

Lead time aggregation may occur when the upstream is out of stock at the time of placing an order by the downstream. Such orders are delayed as long as they can be supplied by the upstream. In the proposed model, lead times can be aggregated to create a long unpredictable lead time for the downstream. In order to deal with these uncertainties and also to achieve a considerable reduction in SC costs, a semi-shaper strategy based on shifting the upstream reorder points to a higher position is adopted. When the upstream replenishes sooner, the probability of lead time aggregation is diminished.

\section{Model Preparations}

Consider a three-echelon supply chain in the presence of stochastic lead times for upstream members assuming a fixed and known demand. Unlike the upstream members, lead time for the retailer is fixed and known. If possible, the retailer does not like to be confronted with a shortage. Therefore, if lead time aggregation does not occur, the retailer prevents from shortage by adjusting its reorder point on $D . L_{r}$, where $D$ is demand rate and $L_{r}$ is the retailer lead time. In this way, the retailer order size $Q$ is issued when the retailer inventory level reaches the reorder point $s_{r}$. The issued order will be delivered after a fixed lead time $L_{r}$. Note that the distributor can supply the retailer's order when there are enough inventories in the warehouse. The distributor order size is a positive integer multiplier of the retailer order quantity, i.e. $n Q$. The distributor replenishes its stock when inventory level reaches the distributor reorder point $s_{d}$. The distributor order will deliver after a stochastic lead time $L_{d}$. It is assumed that $L_{d}$ follows a truncated normal distribution in $[0, \infty)$ with known mean and variance. A batch production system with stochastic lead time $L_{p}$ for the producer is assumed. Also, the producer lead time follows a truncated normal distribution in $[0, \infty)$ with known mean and variance. The production batch in the producer site is a positive integer multiplier of the distributor order size, i.e. $p n Q$. By using truncated normal distribution, it is ensured that lead times will never become less than zero.

According to the major literature in the inventory control area, shortage cost is considered for the member who is directly associated with customers; i.e. retailers. Similarly, in the present paper, it is assumed that the retailer who is connected directly to customers incurs shortage cost. In other words, upstream members do not face any penalty for late deliveries.

Obviously, the retailer and distributor lead times aggregate if the distributor lead time exceeds the moment of placing an order by the retailer. Similarly, if at the moment of issuing an order by the distributor, the producer is not able to ship due to uncompleted production process, the distributor and the producer lead times will be aggregated.

There are three scenarios for the retailer replenishment cycles: 
(1) Cycles in which only the retailer starts to do replenishment and the distributor and the producer (if needed) ship the orders from their stocks.

(2) Cycles in which the distributor needs to ship the retailer's order from new-entrant inventory. In this case, aggregation of the retailer and distributor lead times may occur once the inventory is in-transit and has not been entered into the distributor warehouse.

(3) Cycles where both the distributor and producer wait for new-entrant inventories, in which there is the probability for aggregation of all lead times.

\subsection{Assumptions}

- The retailer lead time is fixed while both upstream members face stochastic lead times for replenishing their stock.

- Only the retailer who is connected directly to customers incurs shortage cost and upstream members do not incur any penalty for delayed orders.

- To create a more realistic case, it is assumed that there is maximum possible duration to store products in the distributor and producer sites. These durations are equal to $a$ and $b$ time units for the distributor and producer, respectively.

- Aggregated lead times follow a normal distribution.

\subsection{Notations and Definitions}

The following notations are applied in the proposed mathematical models:

$D$ : Demand rate per year

$Q$ : Retailer order quantity

$h_{r}, h_{d}, h_{p}$ : Inventory holding costs per item per year for the retailer, distributor, and producer, respectively

$A_{r}, A_{d}, A_{p}$ : Ordering cost per replenishment for the retailer, distributor, and producer, respectively

$B_{r}$ : Retailer shortage cost per item

$n, p$ : Distributor and producer ordering multipliers, respectively (decision variable)

$a, b$ : Maximum possible duration (in years) for stocking products at the distributor and producer sites, respectively

$K_{r}$ : Retailer's expected annual shortage cost

$h z_{d}, h z_{p}$ : Expected surplus inventory holding cost during a year for the distributor and producer, respectively

$s_{r}, s_{d}, s_{p}$ : Reorder point for the retailer, distributor, and producer, respectively

$L_{r}, L_{d}, L_{p}$ : Lead times of the retailer, distributor, and producer, respectively 
$Y, Z$ : Random variables representing the distributor and producer lead times, respectively; $Y \sim N\left(\lambda_{2}, \varepsilon_{2}^{2}\right), Z \sim N\left(\lambda_{3}, \varepsilon_{3}^{2}\right)$

$\lambda_{2}, \lambda_{3}$ : Expected values of the distributor and producer lead times, respectively

$\varepsilon_{2}, \varepsilon_{3}$ : Standard deviations of the distributor and producer lead times, respectively

$\varphi$ : Coefficient of the distributor reorder point $\left(s_{d}\right.$ is calculated as $(\varphi-1) Q$ and thus $\varphi$ should be a positive integer less than or equal to $n$ ) (decision variable)

$\tau$ : Coefficient of the producer reorder point $\left(s_{p}\right.$ is calculated as $(\tau-1) n Q$; thus, $\tau$ should be a positive integer less than or equal to $p$ ) (decision variable)

$W_{r}, W_{d}$ : Retailer and distributor replenishment cycles, respectively

$V_{r_{-} d}:$ A random variable equal to $Y-\varphi W_{r}$; in a particular replenishment cycle, $V_{r_{-} d}>0$ indicates the aggregation of both retailer and distributor lead times, while $V_{r_{-} d} \leq 0$ indicates that aggregation does not occur; as a result, the distributor would be forced to hold surplus inventory. Since both the retailer lead time and demand are fixed, then the retailer replenishment cycle $W_{r}$ is fixed. Therefore, $V_{r_{-} d}$ is a random variable; $V_{r_{-} d} \sim N\left(\lambda_{2}-\varphi \frac{Q}{D}, \varepsilon_{2}^{2}\right)$.

$V_{p_{-} d}:$ A random variable equal to $Z-\tau W_{d}$; in a particular replenishment cycle, $V_{p_{-} d}>0$ indicates the aggregation of both distributor and producer lead times, while $V_{p_{-} d} \leq 0$ indicates that aggregation does not occur; as a result, the producer would be forced to hold surplus inventory.

$g_{r}$ : A random variable representing length of the aggregated lead times of the distributor and retailer

The aggregation of both distributer and retailer lead times occurs only when $V_{r_{-} d}$ is greater than zero; if it gets a value less than zero, no aggregation will occur. So, the duration of aggregated lead time in this case can be expressed as the sum of $V_{r_{-} d}$ value when it is greater than zero (i.e. $\left.V_{r_{-} d} \mid V_{r_{-} d}>0\right)$ and the retailer lead time:

$g_{r}=\left[V_{r_{-} d} \mid V_{r_{-} d}>0\right]+L_{r}$

$g_{d}$ : A random variable representing length of the aggregated lead times of the distributor and producer

The aggregation of both distributer and producer lead times occurs only when $V_{p_{-} d}$ is greater than zero; if it gets a value less than zero, no aggregation will occur. So, the duration of the 
aggregated lead time in this case is equal to the sum of $V_{p_{-} d}$ value when it is greater than zero (i.e. $V_{p_{-} d} \mid V_{p_{-} d}>0$ ) and the distributer lead time:

$g_{d}=\left[V_{p_{-}} \mid V_{p_{-} d}>0\right]+\mathrm{Y}$

$g_{p}$ : A random variable representing length of the aggregated lead times of the producer, distributor, and retailer when all the lead times are long enough to be aggregated. It occurs only when both $V_{r_{-} d}$ and $V_{p_{-} d}$ are greater than zero simultaneously. So, duration of the aggregated lead time in this case is equal to sum of the values of $V_{r_{-} d}$ and $V_{p_{-} d}$ when they are greater than zero $\left(V_{r_{-} d}\left|V_{r_{-} d}>0, V_{p_{-} d}\right| V_{p_{-} d}>0\right)$ and the retailer lead time:

$g_{p}=\left[V_{r_{-} d} \mid V_{r_{-} d}>0, V_{p_{-} d}>0\right]+\left[V_{p_{-} d} \mid V_{p_{-} d}>0, V_{r_{-} d}>0\right]+L_{r}$

$g_{\mathrm{e}}$ : A random variable representing aggregated lead times of the producer and retailer when the distributor lead time is not long enough to be aggregated. It occurs only when $V_{p_{-} d}$ is greater than zero (it means that aggregation happens between the distributer and producer) and $V_{r_{-} d}$ is less than zero (it means that the aggregation between the retailer and distributer does not happen). In this case, short lead time of the distributor causes a negative value for $V_{r_{-} d}$; this negative value has a subtractive effect on $g_{e}$. Therefore, duration of lead time aggregation in this case can be calculated by:

$g_{\mathrm{e}}=\operatorname{Max}\left(0,\left[V_{p_{-} d} \mid V_{p_{-} d}>0\right]-\left[V_{r_{-} d} \mid V_{r_{-} d}<0\right]\right)+L_{r}$

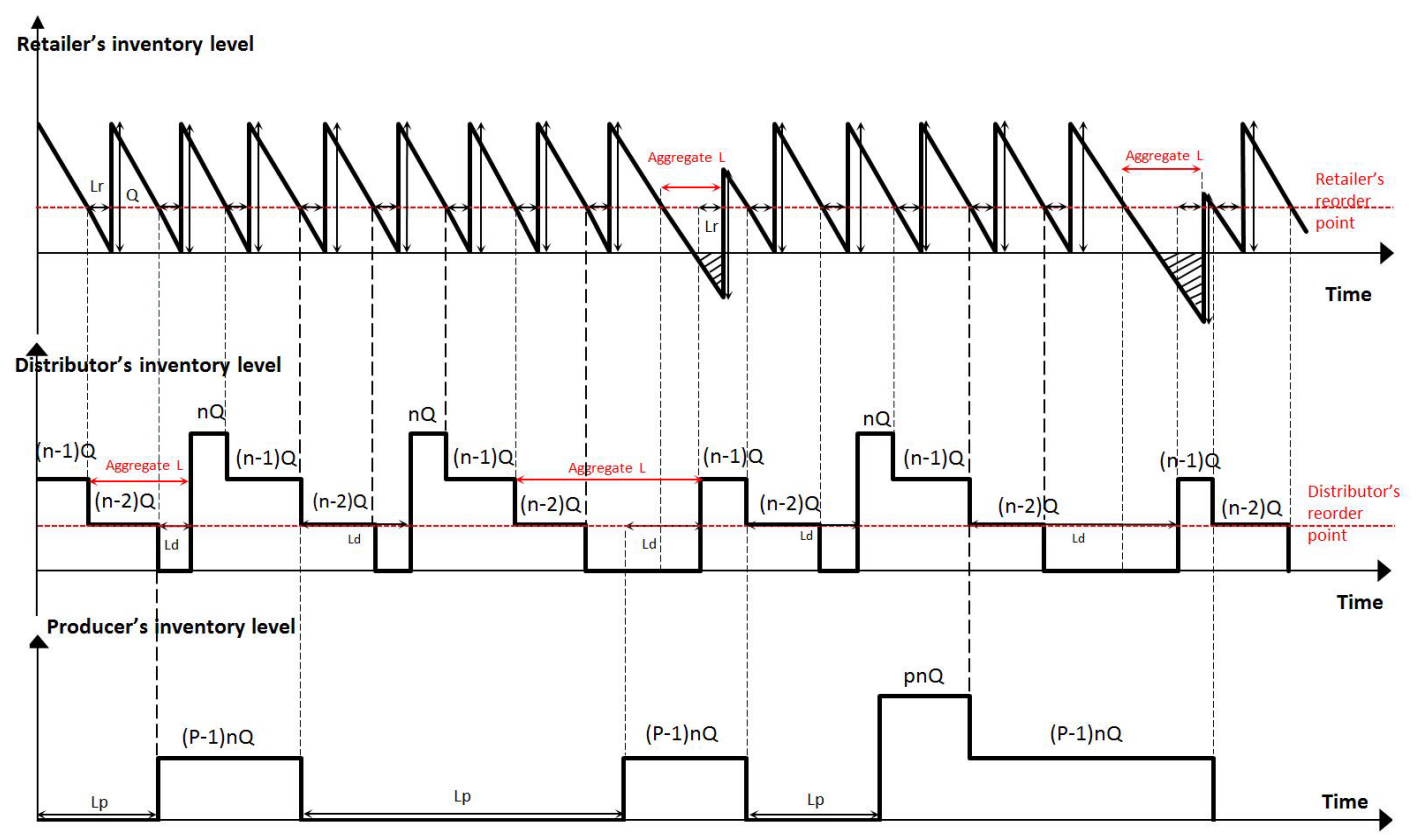

Figure 1. Inventory level of the retailer, distributor, and producer in three replenishment cycles of producer $(\mathrm{p}=2, \tau=1, \mathrm{n}=3, \varphi=2)$ 
Figure 1 shows an instance of the inventory levels for all the three SC members with $n=3$, $p=2, \varphi=2$, and $\tau=1$. As shown in Figure 1, in the cycles in which only the retailer starts to replenish and upstream members ship the orders from their stocks, there is no possibility for the aggregation of lead times. However, in other cycles in which one or both upstream members wait for receiving own orders, the aggregation of lead times may occur depending on upstream lead time length. As a direct result, the likelihood of shortages in the retailer site increases.

\section{Model Formulations}

In the investigated SC, upstream lead times are stochastic; therefore, the length of replenishment cycles for upstream members is also a stochastic variable. The retailer replenishes $\frac{D}{Q}$ times per year. So, the retailer replenishment cycle, i.e. $W_{r}$, will be $\frac{Q}{D}$. However, length of the distributor replenishment cycle is stochastic. The distributor replenishes $\frac{D}{n Q}$ times per year on average. Thus, the distributor replenishment cycle, i.e. random variable $W_{d}$, follows a normal distribution with the mean of $\frac{n Q}{D}$ and variance of $\varepsilon_{2}^{2}$ (it is equivalent to variance of the distributor's lead time).

In this paper, for acquiring the mean and variance of random variables $V_{p_{-} d}, g_{r}, g_{d}, g_{p}$, and $g_{e}$, a simulation study was implemented. To calculate the above-mentioned parameters, at first, 1000 normally distributed random numbers for $Y$ and $Z$ with the means of $\lambda_{2}$ and $\lambda_{3}$ as well as standard deviations of $\varepsilon_{2}$ of $\varepsilon_{3}$ were respectively generated and, then, mean and variance for the above random variables were calculated.

The probability of holding surplus inventory by the producer can be expressed as:

$p\left(Z \leq \tau W_{d}\right)=p\left(Z-\tau W_{d} \leq 0\right)=p\left(V_{p_{-} d} \leq 0\right)=\int_{-\infty}^{0} f\left(V_{p_{-} d}\right) d V_{p_{-} d}$

The probability of the aggregation of the producer and distributor lead times is:

$p\left(Z>\tau W_{d}\right)=p\left(Z-\tau W_{d}>0\right)=p\left(V_{p_{-} d}>0\right)=\int_{0}^{\infty} f\left(V_{p_{-} d}\right) d V_{p_{-} d}$

The probability of holding surplus inventory by the distributor can be calculated by:

$p\left(Y \leq \varphi W_{r}\right)=p\left(Y-\varphi W_{r} \leq 0\right)=p\left(V_{r_{-} d} \leq 0\right)=\int_{-\infty}^{0} f\left(V_{r_{-} d}\right) d V_{r_{-} d}=\int_{0}^{\varphi W_{r}} f(Y) d Y$

The probability of the aggregation of the distributor and retailer lead times is:

$p\left(Y>\varphi W_{r}\right)=p\left(Y-\varphi W_{r}>0\right)=p\left(V_{r_{-} d}>0\right)=\int_{0}^{\infty} f\left(V_{r_{-} d}\right) d V_{r_{-} d}=\int_{\varphi W_{r}}^{\infty} f(Y) d Y$

\subsection{Decentralized decision making}

Under decentralized decision making model, each member decides based on its own profit. The distributor decides on order size and reorder point through optimizing $n$ and $\varphi$. Similarly, the producer decides on $p$ and $\tau$. Below, decision making models of all the three SC members under decentralized decision making are analyzed. 


\subsubsection{The retailer model}

The retailer cost function is composed of ordering, holding, and shortage costs.

The retailer expected shortage cost can be formulated as:

$E B_{r}=$

$\left(1-\frac{1}{n}\right) \frac{B_{r} D}{Q}($ Zero $)+$

$\left(\frac{1}{n}-\frac{1}{n p}\right) \frac{B_{r} D}{Q}\left[\left(\int_{0}^{\varphi W_{r}} f(Y) d Y\right)(Z\right.$ ero $\left.)+\left(\int_{\varphi W_{r}}^{\infty} f(Y) d Y\right)\left(D \int_{\frac{s_{r}}{D}}^{\infty}\left(g_{r}-\frac{s_{r}}{D}\right) f\left(g_{r}\right) d g_{r}\right)\right]+$

$\frac{1}{n} \frac{B_{r} D}{Q}\left[\left(\int_{-\infty}^{0} f\left(V_{p_{-} d}\right) d V_{p_{-} d}\right)\left(\int_{0}^{\varphi W_{r}} f(Y) d Y\right)(\right.$ Zero $)+$

$\left(\int_{-\infty}^{0} f\left(V_{p_{-} d}\right) d V_{p_{-} d}\right)\left(\int_{\varphi W_{r}}^{\infty} f(Y) d Y\right)\left(D \int_{\frac{s_{r}}{D}}^{\infty}\left(g_{r}-\frac{s_{r}}{D}\right) f\left(g_{r}\right) d g_{r}\right)+$

$\left(\int_{0}^{\infty} f\left(V_{p_{-} d}\right) d V_{p_{-} d}\right)\left(\int_{0}^{\varphi W_{r}} f(Y) d Y\right)\left(D \int_{\frac{s_{r}}{D}}^{\infty}\left(g_{e}-\frac{s_{r}}{D}\right) f\left(g_{e}\right) d g_{e}\right)+$

$\left.\left(\int_{0}^{\infty} f\left(V_{p_{-} d}\right) d V_{p_{-} d}\right)\left(\int_{\varphi W_{r}}^{\infty} f(Y) d Y\right)\left(D \int_{\frac{s_{r}}{D}}^{\infty}\left(g_{p}-\frac{s_{r}}{D}\right) f\left(g_{p}\right) d g_{p}\right)\right]$

The retailer shortage cost (Equation 5) is composed of three parts: The first part represents shortage cost when other members do not replenish, which occurs in $\left(1-\frac{1}{n}\right) \%$ of cycles. Obviously, by assuming a fixed lead time with known and fixed demand for the retailer, zero shortage happens according to the retailer replenishment policy. The second part represents shortage cost when both distributor and retailer replenish their stocks simultaneously, while the producer does not replenish, which happens in $\left(\frac{1}{n}-\frac{1}{n p}\right) \%$ of cycles. The second term includes two parts:

(1) When no lead time aggregation occurs so that the retailer does not incur any shortages. In other words, shortage equals zero.

(2) When aggregation of both retailer and distributor lead times occurs.

The last term represents shortage cost when all the SC members replenish their inventory simultaneously, which occurs in $\frac{1}{n p} \%$ of cycles and includes four scenarios:

(1) Lead time aggregation between members does not occur; i.e. zero shortage happens.

(2) Lead time aggregation occurs only between the retailer and distributor.

(3) Lead time aggregation occurs only between the distributor and producer.

(4) Lead time aggregation occurs between all three members.

The retailer expected cost function can be formulated as:

$T C_{r}=\frac{D}{Q} A_{r}+h_{r}\left(\frac{Q}{2}\right)+E B_{r}$

where the first term denotes ordering cost, second term stands for inventory holding cost, and third term represents shortage costs. 


\subsubsection{The distributor decision model}

Under decentralized model, the distributor decides based on its own cost function. The distributor expected inventory holding cost per year can be formulated as:

$E h_{d}=h_{d}\left[\max \left\{\left(\frac{(n-1) Q}{2}\right)-\frac{D}{n Q}\left(\sum_{i=1} \min \left(\left[\frac{\int_{0}^{\infty}\left(Y-\varphi W_{r}\right) f\left(V_{r_{-} d}\right) d V_{r_{-}} d}{\frac{Q}{D}}\right], n-1\right){ }_{(n-i) Q \frac{Q}{D}}\right)-\right.\right.$

$\frac{D}{n Q}\left((n-1)-\min \left(\left\lfloor\frac{\int_{0}^{\infty}\left(Y-\varphi W_{r}\right) f\left(V_{r_{-}}\right) d V_{r_{-} d}}{\frac{Q}{D}}\right\rfloor, n-1\right)\right) Q\left(\int_{0}^{\infty}\left(Y-\varphi W_{r}\right) f\left(V_{r_{-} d}\right) d V_{r_{-} d}-\right.$

$\left.\left.\left.\frac{Q}{D}\left[\frac{\int_{0}^{\infty}\left(Y-\varphi W_{r}\right) f\left(V_{r_{-}}\right) d V_{r_{-}}}{\frac{Q}{D}}\right]\right), 0\right\}\right]$

Further details on the calculation of Equation (7) are provided in the appendix.

The distributor annual expected cost function can be expressed as:

Min $T C_{d}(n, \varphi)=\frac{D}{n Q} A_{d}+E h_{d}+h_{d} \frac{D}{n Q} n Q\left(\int_{-\infty}^{0}\left(\varphi W_{r}-Y\right) f\left(V_{r_{-} d}\right) d V_{r_{-} d}\right)$

s.t. $1 \leq n \leq\left[\frac{a D}{Q}\right]$

$1 \leq \varphi \leq n$

$n, \varphi \in \mathbb{Z}$

where the first term denotes ordering cost, second term represents inventory holding cost per year, and third term calculates cost of holding expected surplus inventory when the distributor has to keep surplus inventory; i.e. when $V_{r_{-} d} \leq 0$.

\subsubsection{The producer decision model}

The producer also decides on replenishment decision variables $p$ and $\tau$ based on its cost function. The producer expected inventory holding cost per year can be formulated as:

$E h_{p}=h_{p}\left[\max \left\{\left(\frac{(p-1) n Q}{2}\right)-\frac{D}{p n Q}\left(\sum_{j=1}^{\min \left(\mid \int_{0}^{\infty}\left(Z-\tau W_{d}\right) f\left(v_{p_{-}}\right) d V_{p_{-}} d\right.} \frac{n Q}{D}, p-1\right)(p-j) n Q \frac{n Q}{D}\right)-\right.$

$\frac{D}{p n Q}\left((p-1)-\min \left(\left\lfloor\frac{\int_{0}^{\infty}\left(Z-\tau W_{d}\right) f\left(V_{p_{-} d}\right) d V_{p_{-} d}}{\frac{n Q}{D}}\right\rfloor, p-1\right)\right) n Q\left(\int_{0}^{\infty}\left(Z-\tau W_{d}\right) f\left(V_{p_{-} d}\right) d V_{p_{-} d}-\right.$

$\left.\left.\left.\frac{n Q}{D}\left[\frac{\int_{0}^{\infty}\left(Z-\tau W_{d}\right) f\left(V_{p_{-}}\right) d V_{p_{-}}}{\frac{n Q}{D}}\right]\right), 0\right\}\right]$

Details for Equation (9) are the same as those for Equation (7) that can be found in the appendix 
The producer annual expected cost can be formulated as:

Min $T C_{p}(p, \tau)=\frac{D}{p n Q} A_{p}+E h_{p}+h_{p} \frac{D}{p n Q} p n Q\left(\int_{-\infty}^{0}\left(\tau W_{d}-Z\right) f\left(V_{p_{-} d}\right) d V_{p_{-} d}\right)$

s.t. $1 \leq p \leq\left[\frac{b D}{n Q}\right]$

$$
\begin{aligned}
& 1 \leq \tau \leq p \\
& p, \tau \in \mathbb{Z}
\end{aligned}
$$

where the first term denotes expected ordering cost, second term represents expected inventory holding cost per year, and third part represents surplus inventory holding cost which is composed of four parts: (1) $h_{p}$ which is the producer inventory holding cost per unit, (2) $\frac{D}{p n Q}$ as the expected number of replenishment cycles per year, (3) $p n Q$ as the level of surplus inventory when $V_{p_{-} d} \leq 0$, and (4) expected duration per cycle in which the producer should hold surplus inventory; i.e. $\left(\int_{-\infty}^{0}\left(\tau W_{d}-Z\right) f\left(V_{p_{-} d}\right) d V_{p_{-} d}\right)$.

\subsection{Centralized decision making}

Under centralized decision making, there is a single decision maker who is responsible for managing the entire SC. This single decision maker intends to minimize the whole SC costs. Expected cost function of the whole SC is equal to the sum of SC members cost functions. Expected cost function of SC per year can be formulated as:

Min $T C_{s c}(n, \varphi, p, \tau)=\frac{D}{Q}\left[A_{r}+\frac{A_{d}}{n}+\frac{A_{p}}{n p}\right]+D\left[h_{p} \int_{-\infty}^{0}\left(\tau W_{d}-Z\right) f\left(V_{p_{-} d}\right) d V_{p_{-} d}+\right.$

$$
\left.h_{d} \int_{-\infty}^{0}\left(\varphi W_{r}-Y\right) f\left(V_{r_{-} d}\right) d V_{r_{-} d}\right]+\frac{h_{r} Q}{2}+E h_{p}+E h_{d}+E B_{r}
$$

s.t. $1 \leq n \leq\left[\frac{a D}{Q}\right]$

$$
\begin{aligned}
& 1 \leq p \leq\left[\frac{b D}{n Q}\right] \\
& 1 \leq \varphi \leq n \\
& 1 \leq \tau \leq p \\
& n, \varphi, p, \tau \in \mathbb{Z}
\end{aligned}
$$

To find optimal values of decision variables under the centralized model, the following search algorithm is proposed:

Step 1: Assign the lowest possible value to $n$;

Step 2: Assign the lowest possible value to $\varphi$;

Step 3: Assign the lowest possible value to $p$;

Step 4: Assign the lowest possible value to $\tau$;

Step 5: Calculate and save total SC cost using Equation (11) for the current set $(n, \varphi, p, \tau)$;

Step 6: If $\tau<p$, then $\tau=\tau+1$ and return to step 5;

Step 7: If $p<\left\lfloor\frac{b D}{n Q}\right\rfloor$, then $p=p+1$ and return to step 4;

Step 8: If $\varphi<n$, then $\varphi=\varphi+1$ and return to step 3; 
Step 9: If $n<\left\lfloor\frac{a D}{Q}\right\rfloor$, then $n=n+1$ and return to step 2;

Step 10: A combination of $n, \varphi, p$, and $\tau$ which returns the lowest $T C_{s c}$ is optimum. The above search algorithm can search the solution space in a reasonable CPU time. The procedure for calculating decision variables under the decentralized setting is less complicated. Under the decentralized setting, since there is no penalty for delayed orders for the upstream members, they set their reorder points as low as possible, i.e. $\varphi=1$ and $=1$. Values of $n$ and $p$ under the decentralized setting can be calculated using a simple search algorithm, like the introduced algorithm for the centralized model; but, the algorithm does not need to calculate reorder point coefficients $\varphi$ and $\tau$. In addition, under the decentralized setting, the algorithm should be separately run for each of the two upstream members: first, for the distributor to calculate optimal $n$ and, second, for the producer to calculate optimal $p$.

However, it is expected from the centralized decision making to result in higher values for $\varphi$ and $\tau$ than the decentralized model.

It is expected from SC total cost under the centralized decision making to be less than the decentralized decision making model. However, it does not mean a cost reduction for all SC members. Therefore, the centralized decision making model is not applicable without appropriate arrangements for the members who have been affected. In the next section, an appropriate mechanism for shifting from the decentralized to centralized models is proposed.

Subscripts 1, 2, and 3 in the proposed coordination mechanism denote optimal solutions under decentralized, centralized, and coordinated decision making models, respectively.

\subsection{Coordinated model: Transition from decentralized to centralized model}

Transition from decentralized to centralized model needs an incentive scheme for SC members who lose profit during this transition. Due to reduced shortage costs, the retailer benefits from this transition, while the upstream members, i.e. the distributor and producer, may be faced with increased costs due to holding surplus inventory resulted from increased reorder points. The proposed incentive scheme has some unique features in dividing profit between the members; the proposed scheme has two main phases: (1) compensating phase and (2) rewarding phase.

The basic idea of the proposed incentive scheme is sharing the retailer's earned benefit with two upstream members. In the compensating phase, to compensate for the increased inventory costs of upstream members, the retailer pays the distributor $\alpha$ percent of the earned profit from the reduced shortage costs and also pays $\beta$ percent to the producer. In this way, $\alpha$ and $\beta$ should be determined such that the total cost of the distributor and producer does not increase after shifting from decentralized to centralized model. Therefore, applying $\alpha$ and $\beta$ compensates for the increased cost of both upstream members.

Based on the above explanation, $\alpha$ and $\beta$ must satisfy the following conditions:

$T C_{d}\left(\varphi_{2}, n_{2}\right)-T C_{d}\left(\varphi_{1}, n_{1}\right)=\alpha \Delta K_{r}$ 
$T C_{p}\left(\tau_{2}, p_{2}\right)-T C_{p}\left(\tau_{1}, p_{1}\right)=\beta \Delta K_{r}$

Left-hand side of Equations (12) and (13) denotes the increase in total costs of the distributor and producer, respectively. Right-hand side of Equations (12) and (13) denotes $\% \alpha$ and $\% \beta$ of saved shortage costs at the retailer site in shifting from decentralized to centralized model. Therefore, $\alpha$ and $\beta$ can be calculated as:

$$
\begin{aligned}
& \alpha=\max \left\{0,\left[\frac{T C_{d}\left(\varphi_{2}, n_{2}\right)-T C_{d}\left(\varphi_{1}, n_{1}\right)}{K_{r 1}-K_{r 2}}\right]\right\} \\
& \beta=\max \left\{0,\left[\frac{T C_{p}\left(\tau_{2}, p_{2}\right)-T C_{p}\left(\tau_{1}, p_{1}\right)}{K_{r 1}-K_{r 2}}\right]\right\}
\end{aligned}
$$

Note that $\alpha$ and $\beta$ are paid values by the retailer to the distributor and producer, respectively; therefore, $\alpha$ and $\beta$ should not take negative values. To avoid negative values for $\alpha$ and $\beta$, Equations (14) and (15) are written in the form of $\max (0, v a l u e)$. To ensure retailer savings from centralized decision making is greater than the imposed costs to the upstream members, it is necessary that the sum of $\alpha$ and $\beta$ be less than one.

When upstream members have more bargaining powers than the retailer, in addition to compensation for their costs using coefficients $\alpha$ and $\beta$, they expect to receive a reasonable share of earned benefits. Therefore, there is a need for a rewarding phase. In this case, to entice upstream members to participate in the scheme, the retailer undertakes $\theta$ percent of the distributor's surplus inventory holding costs and $\gamma$ percent of the producer's surplus inventory holding costs. The basic idea for determining $\theta$ and $\gamma$ can be expressed as: "more efforts are rewarded more". Based on this idea, $\theta$ and $\gamma$ are determined in proportion to the imposed costs to the distributor and producer in shifting from decentralized to centralized model. If the imposed cost to the distributor compared with reduced total SC cost becomes greater, the distributor is eligible for more reward and, as a result, $\theta$ takes a greater value. This scheme is similar for the producer. Note that $\theta$ and $\gamma$ could not take negative values; therefore, we have:

$$
\begin{aligned}
& \theta=\max \left\{0,\left[\frac{T C_{d}\left(\varphi_{2}, n_{2}\right)-T C_{d}\left(\varphi_{1}, n_{1}\right)}{T C_{s c}\left(\varphi_{1}, n_{1}, \tau_{1}, p_{1}\right)-T C_{s c}\left(\varphi_{2}, n_{2}, \tau_{2}, p_{2}\right)}\right]\right\} \\
& \gamma=\max \left\{0,\left[\frac{T C_{p}\left(\tau_{2}, p_{2}\right)-T C_{p}\left(\tau_{1}, p_{1}\right)}{T C_{s c}\left(\varphi_{1}, n_{1}, \tau_{1}, p_{1}\right)-T C_{s c}\left(\varphi_{2}, n_{2}, \tau_{2}, p_{2}\right)}\right]\right\}
\end{aligned}
$$

Finally, paying $\theta$ percent and $\gamma$ percent of the imposed surplus inventory holding cost to a member is the reward of participation in the SC coordination scheme. Therefore, cost of upstream members under coordination can be expressed as: 


$$
\begin{aligned}
& T C_{d}\left(\varphi_{3}, n_{3}\right)=T C_{d}\left(\varphi_{2}, n_{2}\right)-\alpha \Delta K_{r}-\theta\left[\frac{h_{d} D}{n_{2} Q} n_{2} Q\left(\int_{-\infty}^{0}\left(\varphi_{2} W_{r}-Y\right) f\left(V_{r_{-} d}\right) d V_{r_{-} d}\right)\right] \\
& \left.T C_{p}\left(\tau_{3}, p_{3}\right)=T C_{p}\left(\tau_{2}, p_{2}\right)-\beta \Delta K_{r}-\gamma\left[\frac{h_{p} D}{p_{2} n_{2} Q} p_{2} n_{2} Q\left(\int_{-\infty}^{0}\left(\tau_{2} W_{d}-Z\right) f\left(V_{p_{-} d}\right) d V_{p_{-} d}\right)\right)\right]
\end{aligned}
$$

\section{Numerical experiments}

To investigate the performance of the proposed models, a set of test problems is examined. Decentralized, centralized, and coordinated decision making models are numerically investigated. Data for the 10 investigated test problems are shown in Table 2.

Table 2. Data for the investigated test problems

\begin{tabular}{lllllllllll}
\hline $\begin{array}{l}\text { Test } \\
\text { problem } \\
\text { number }\end{array}$ & $\begin{array}{l}\text { Test } \\
\text { problem 1 } 1\end{array}$ & $\begin{array}{l}\text { Test } \\
\text { problem 2 }\end{array}$ & $\begin{array}{l}\text { Test } \\
\text { problem 3 }\end{array}$ & $\begin{array}{l}\text { Test } \\
\text { problem 4 } 4\end{array}$ & $\begin{array}{l}\text { Test } \\
\text { problem } 5\end{array}$ & $\begin{array}{l}\text { Test } \\
\text { problem 6 }\end{array}$ & $\begin{array}{l}\text { Test } \\
\text { problem 7 7 }\end{array}$ & $\begin{array}{l}\text { Test } \\
\text { problem 8 }\end{array}$ & $\begin{array}{l}\text { Test } \\
\text { problem } 9\end{array}$ & $\begin{array}{l}\text { Test } \\
\text { problem 10 }\end{array}$ \\
\hline$D$ & 15000 & 10000 & 5000 & 7000 & 10000 & 3000 & 6000 & 9000 & 12000 & 20000 \\
$Q$ & 500 & 300 & 200 & 600 & 600 & 150 & 250 & 250 & 900 & 700 \\
$h_{r}$ & 9 & 7 & 7.5 & 10 & 8 & 9 & 8 & 9 & 10 & 10.5 \\
$h_{d}$ & 6 & 3 & 5.5 & 8 & 5 & 6 & 7.5 & 4 & 9 & 5.5 \\
$h_{p}$ & 1 & 2 & 0.5 & 3 & 1.5 & 2 & 4 & 3 & 8 & 1 \\
$A_{r}$ & 350 & 100 & 100 & 70 & 200 & 65 & 80 & 75 & 370 & 360 \\
$A_{d}$ & 200 & 85 & 140 & 90 & 270 & 75 & 95 & 180 & 300 & 230 \\
$A_{p}$ & 100 & 70 & 400 & 100 & 350 & 95 & 105 & 300 & 250 & 100 \\
$B_{r}$ & 3.5 & 3.5 & 2.5 & 8.5 & 3 & 4 & 2 & 4 & 7 & 4.5 \\
$L_{r}$ (Day) & 6 & 9 & 8 & 10 & 15 & 7 & 22 & 7 & 28 & 4 \\
$\lambda_{2}$ (Day) & 30 & 25 & 36 & 42 & 12 & 4 & 37 & 32 & 34 & 26 \\
$\lambda_{3}$ (Day) & 48 & 35 & 40 & 48 & 5 & 30 & 54 & 46 & 14 & 50 \\
$\varepsilon_{2}$ (Day) & 6 & 12 & 5 & 4 & 7 & 1 & 17 & 6 & 15 & 7 \\
$\varepsilon_{3}$ (Day) & 10 & 20 & 10 & 15 & 1 & 15 & 26 & 18 & 6 & 23 \\
$a$ (Month) & 2 & 1 & 3 & 3 & 4 & 1 & 2 & 1 & 2 & 2 \\
$b$ (Month) & 3 & 4 & 5 & 5 & 5 & 4 & 5 & 4 & 4 & 6 \\
\hline
\end{tabular}

Results for three decision making models, i.e. decentralized, centralized, and coordinated, are shown in Table 3, in which $K_{r}$ stands for the retailer's expected annual shortage cost, $h z_{d}$ denotes the distributor's expected surplus inventory holding cost during a year, and $h z_{p}$ shows the producer's expected surplus inventory holding cost per year. By comparing decentralized and centralized decision making models, it is revealed that centralized decision making gains remarkable profits for the whole SC. However, centralized decision making results in more costs for upstream members and, therefore, upstream members refuse to participate in the centralized decision making model. 
Table 3. Results of decentralized, centralized, and coordinated decision making models for the investigated test problems

\begin{tabular}{|c|c|c|c|c|c|c|c|c|c|c|}
\hline & $\begin{array}{l}\text { Test } \\
\text { problem } 1\end{array}$ & $\begin{array}{l}\text { Test } \\
\text { problem } 2\end{array}$ & $\begin{array}{l}\text { Test } \\
\text { problem } 3\end{array}$ & $\begin{array}{l}\text { Test } \\
\text { problem } 4\end{array}$ & $\begin{array}{l}\text { Test } \\
\text { problem } 5\end{array}$ & $\begin{array}{l}\text { Test } \\
\text { problem } 6\end{array}$ & $\begin{array}{l}\text { Test } \\
\text { problem } 7\end{array}$ & $\begin{array}{l}\text { Test } \\
\text { problem } 8\end{array}$ & $\begin{array}{l}\text { Test } \\
\text { problem } 9\end{array}$ & $\begin{array}{l}\text { Test } \\
\text { problem } 10\end{array}$ \\
\hline \multicolumn{11}{|c|}{ Decentralized model } \\
\hline$n$ & 3 & 2 & 3 & 1 & 2 & 1 & 3 & 3 & 1 & 2 \\
\hline$\varphi$ & 1 & 1 & 1 & 1 & 1 & 1 & 1 & 1 & 1 & 1 \\
\hline$p$ & 2 & 2 & 3 & 2 & 2 & 4 & 1 & 2 & 2 & 2 \\
\hline$\tau$ & 1 & 1 & 1 & 1 & 1 & 1 & 1 & 1 & 1 & 1 \\
\hline$T C_{r}$ & 45913.37 & 35775.82 & 9456.49 & 38813.55 & 5765.39 & 5569.31 & 11189.7 & 38085.71 & 33047.97 & 99445.94 \\
\hline$T C_{d}$ & 2534.66 & 1475.39 & 1362.56 & 1050.69 & 5123.21 & 2202.74 & 1180.56 & 2160.02 & 4960.46 & 3309.69 \\
\hline$T C_{p}$ & 1034.35 & 939.20 & 1443.73 & 1034.42 & 3953.02 & 787.73 & 1408.07 & 2428.43 & 9032.48 & 820.13 \\
\hline$T C_{s c}$ & 49482.38 & 38190.41 & 12262.78 & 40898.66 & 14841.62 & 8559.78 & 13778.33 & 42674.16 & 47040.91 & 103575.76 \\
\hline$K_{r}$ & 33163.37 & 31392.49 & 6206.49 & 34996.88 & 32.06 & 3594.31 & 8269.70 & 34260.71 & 23614.64 & 85485.22 \\
\hline$h z_{d}$ & 0.62 & 58.72 & 0 & 0.69 & 1390.23 & 702.74 & 99.16 & 0.019 & 960.45 & 23.97 \\
\hline$h z_{p}$ & 41.11 & 229.35 & 45.44 & 63.95 & 1594.69 & 30.58 & 568.07 & 161.62 & 4008.10 & 105.84 \\
\hline \multicolumn{11}{|c|}{ Centralized model } \\
\hline$n$ & 3 & 2 & 3 & 2 & 2 & 1 & 4 & 3 & 2 & 3 \\
\hline$\varphi$ & 3 & 2 & 3 & 2 & 1 & 1 & 2 & 3 & 2 & 2 \\
\hline$p$ & 2 & 3 & 3 & 2 & 2 & 4 & 1 & 2 & 1 & 2 \\
\hline$\tau$ & 2 & 3 & 2 & 1 & 1 & 3 & 1 & 2 & 1 & 2 \\
\hline$T C_{r}$ & 13171.04 & 12580.84 & 3256.08 & 5638.97 & 5765.39 & 2101.68 & 5391.23 & 7191.68 & 9780.49 & 19273.69 \\
\hline$T C_{d}$ & 6637.71 & 1878.83 & 2857.54 & 6081.16 & 5123.21 & 2202.74 & 2896.82 & 3111.28 & 12274.13 & 6208.58 \\
\hline$T C_{p}$ & 2284.51 & 3369.56 & 1737.08 & 2971.69 & 3953.02 & 1333.05 & 1688.68 & 4143.02 & 12395.12 & 3047.94 \\
\hline$T C_{s c}$ & 22093.26 & 17829.23 & 7850.70 & 14691.82 & 14841.62 & 5637.47 & 9976.73 & 14445.98 & 34449.74 & 28530.21 \\
\hline$K_{r}$ & 421.04 & 8197.50 & 6.08 & 1822.30 & 32.06 & 126.68 & 2471.23 & 3366.68 & 347.16 & 5312.98 \\
\hline$h z_{d}$ & 1707.64 & 279.13 & 597.28 & 3156.16 & 1390.23 & 702.74 & 492.24 & 166.17 & 6308.54 & 775.53 \\
\hline$h z_{p}$ & 1041.94 & 1979.47 & 325.97 & 921.82 & 1594.69 & 412.25 & 1058.67 & 1335.09 & 10728.45 & 1584.19 \\
\hline \multicolumn{11}{|c|}{ Coordinated model } \\
\hline$n$ & 3 & 2 & 3 & 2 & 2 & 1 & 4 & 3 & 2 & 3 \\
\hline$\varphi$ & 3 & 2 & 3 & 2 & 1 & 1 & 2 & 3 & 2 & 2 \\
\hline$p$ & 2 & 3 & 3 & 2 & 2 & 4 & 1 & 2 & 1 & 2 \\
\hline$\tau$ & 2 & 3 & 2 & 1 & 1 & 3 & 1 & 2 & 1 & 2 \\
\hline$T C_{r}$ & 18827.62 & 15656.45 & 5268.47 & 13280.68 & 5765.39 & 2723.94 & 7688.48 & 9944.23 & 26986.34 & 24477.38 \\
\hline$T C_{d}$ & 2278.85 & 1469.86 & 1160.17 & 444.86 & 5123.21 & 2202.74 & 958.33 & 2154.42 & 1296.09 & 3279.73 \\
\hline$T C_{p}$ & 986.79 & 702.92 & 1422.06 & 966.28 & 3953.02 & 710.79 & 1329.92 & 2347.33 & 6167.31 & 773.1 \\
\hline$T C_{s c}$ & 22093.26 & 17829.23 & 7850.70 & 14691.82 & 14841.62 & 5637.47 & 9976.73 & 14445.98 & 34449.74 & 28530.21 \\
\hline$\alpha$ & 0.125 & 0.017 & 0.241 & 0.151 & 0 & 0 & 0.296 & 0.031 & 0.3143 & 0.0361 \\
\hline$\beta$ & 0.038 & 0.104 & 0.047 & 0.058 & 0 & 0.157 & 0.048 & 0.055 & 0.1445 & 0.0277 \\
\hline $\boldsymbol{\theta}$ & 0.149 & 0.019 & 0.338 & 0.192 & 0 & 0 & 0.451 & 0.033 & 0.5808 & 0.0386 \\
\hline$\gamma$ & 0.045 & 0.119 & 0.066 & 0.074 & 0 & 0.186 & 0.074 & 0.061 & 0.267 & 0.0296 \\
\hline
\end{tabular}

In all the test problems, both the distributor and producer suffer from increased cost under centralized decision making, except test problems 5 and 6. Indeed, in test problem 5, the decentralized solution is optimum from the whole SC viewpoint; therefore, both decentralized and centralized solutions are the same. This situation in test problem 5 occurs because of short 
lead times of two upstream members compared with the retailer's lead time. In other words, their lead times are too short to aggregate with the retailer lead time. Also, in test problem 6, due to the short lead time of the distributor, lead time aggregation between the distributor and retailer does not occur. Consequently, the distributor decisions under decentralized and centralized models are the same. Table 3 shows that SC members will be enticed to participate in the scheme by implementing the proposed incentive mechanism. In other words, all SC members' costs under coordinated decision making model are less than the decentralized model; therefore, all the members have enough motivation to participate in the coordination plan.

Table 3 shows that, under decentralized decision making, upstream members assign the minimum feasible value, i.e. 1, to $\varphi$ and $\tau$ to avoid surplus inventory holding cost. However, as expected, under centralized decision making, these two decision variables take greater amounts in order to reduce shortages at the retailer site, which imposes large costs to the whole SC.

Comparison of $K_{r}, h z_{d}$, and $h z_{p}$ in the decentralized with centralized model reveals that, under decentralized decision making, $K_{r}$ is the key cost factor, while two other ones have a slight impact on total SC costs. Unlike the decentralized model, under the centralized decision making model, $h z_{d}$ and $h z_{p}$ play a key role in the whole SC costs, while $K_{r}$ is significantly reduced in all the test problems (except in test problem 5 as discussed earlier).

To investigate the role of lead times in SC total cost, we investigate effects of changes in lead times on the retailer's shortage cost $K_{r}$ and two upstream members' surplus inventory holding costs, i.e. $h z_{d}$, and $h z_{p}$. A data set similar to test problem 1 is used for sensitivity analyses.

In the sensitivity analyses, we investigate the effects of changing $\lambda_{2}, \lambda_{3}, \varepsilon_{2}, \varepsilon_{3}$ on $K_{r}, h z_{d}$, and $h z_{p}$. For this purpose, three composite variables are defined as $\frac{\left|\Delta k_{r}\right|}{\left|\Delta h z_{d}\right|}, \frac{\left|\Delta k_{r}\right|}{\left|\Delta h z_{p}\right|}$, and $\frac{\left|\Delta k_{r}\right|}{\left|\Delta h z_{p}+\Delta h z_{d}\right|}$, where $\Delta x$ denotes the difference between optimal value of decision variable $x$ in centralized model and decentralized model. It is obvious that, in changing decision structure from decentralized to centralized, $K_{r}$ decreases, while $h z_{d}$ and $h z_{p}$ are expected to increase.

Generally, increasing the expected value of distributor lead time $\lambda_{2}$ leads to an increase in the probability of the distributor and retailer lead times aggregation. Therefore, the retailer's shortage cost may be increased. According to Figure 2, $\Delta k_{r}$ is always greater than $\Delta h z_{d}, \Delta h z_{p}$, and also $\Delta h z_{p}+\Delta h z_{d}$. Therefore, one can conclude that shifting from decentralized to centralized model has more benefits for the retailer than the imposed costs to the upstream members. Fluctuations in the curves of Figure 2 are a direct result of change in optimal values of decision variables by increasing $\lambda_{2}$. Despite these fluctuations, all the curves are always higher than one, which means that benefits of centralized decision making are greater than its costs. 


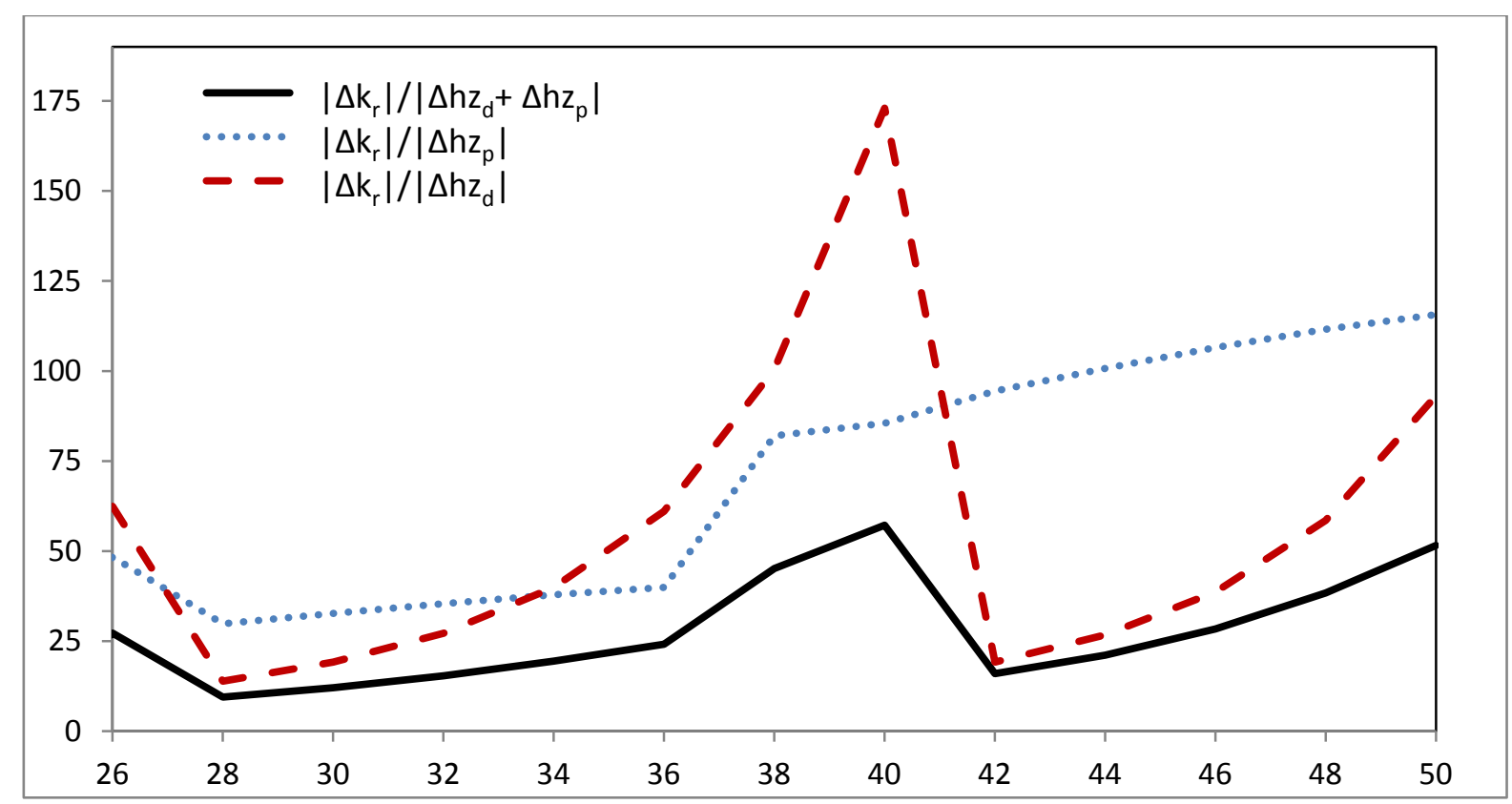

Figure 2. Effects of changing $\lambda_{2}$ on $\frac{\left|\Delta k_{r}\right|}{\left|\Delta h z_{d}\right|}, \frac{\left|\Delta k_{r}\right|}{\left|\Delta h z_{p}\right|}$, and $\frac{\left|\Delta k_{r}\right|}{\left|\Delta h z_{d}+\Delta h z_{p}\right|}$

Figure 3 shows the effects of changes in the expected value of the producer lead time. According to Figure 3 , in all the values of $\lambda_{3}$ benefits of reduced shortages in centralized decision making are more than surplus inventory holding costs of upstream members.

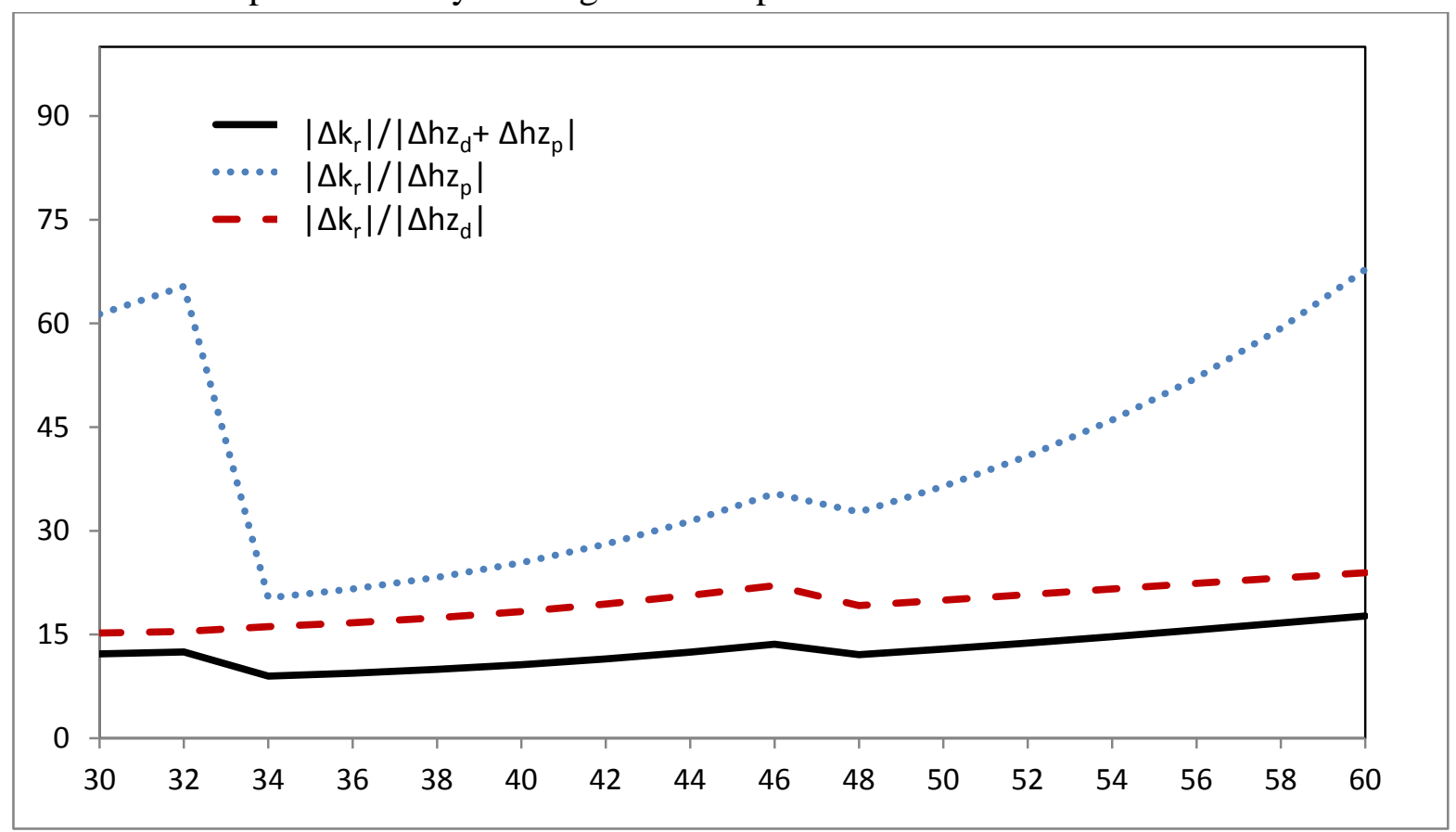

Figure 3. Effects of changing $\lambda_{3}$ on $\frac{\left|\Delta k_{r}\right|}{\left|\Delta h z_{d}\right|}, \frac{\left|\Delta k_{r}\right|}{\left|\Delta h z_{p}\right|}$, and $\frac{\left|\Delta k_{r}\right|}{\left|\Delta h z_{d}+\Delta h z_{p}\right|}$ 
Figures 4 and 5 illustrate the effect of changing $\varepsilon_{2}$ and $\varepsilon_{3}$ on shortage and surplus inventory costs.

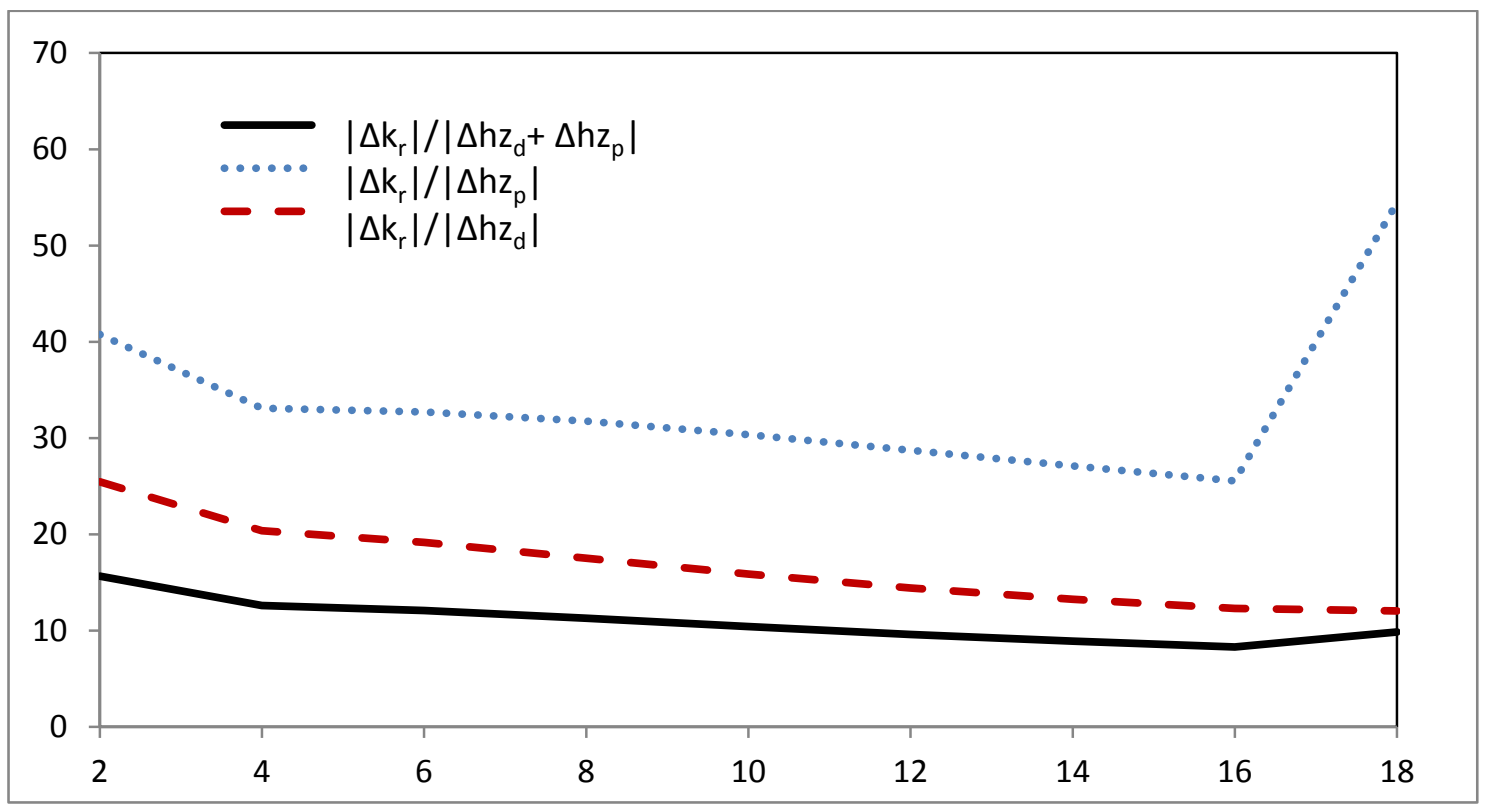

Figure 4. Effects of changing $\varepsilon_{2}$ on $\frac{\left|\Delta k_{r}\right|}{\left|\Delta h z_{d}\right|}, \frac{\left|\Delta k_{r}\right|}{\left|\Delta h z_{p}\right|}$, and $\frac{\left|\Delta k_{r}\right|}{\left|\Delta h z_{d}+\Delta h z_{p}\right|}$

As shown in Figures 4 and 5, in all the values of $\varepsilon_{2}$ and $\varepsilon_{3}, \frac{\left|\Delta k_{r}\right|}{\left|\Delta h z_{d}+\Delta h z_{p}\right|}>1$ which means joint decision making causes more saving for the whole SC.

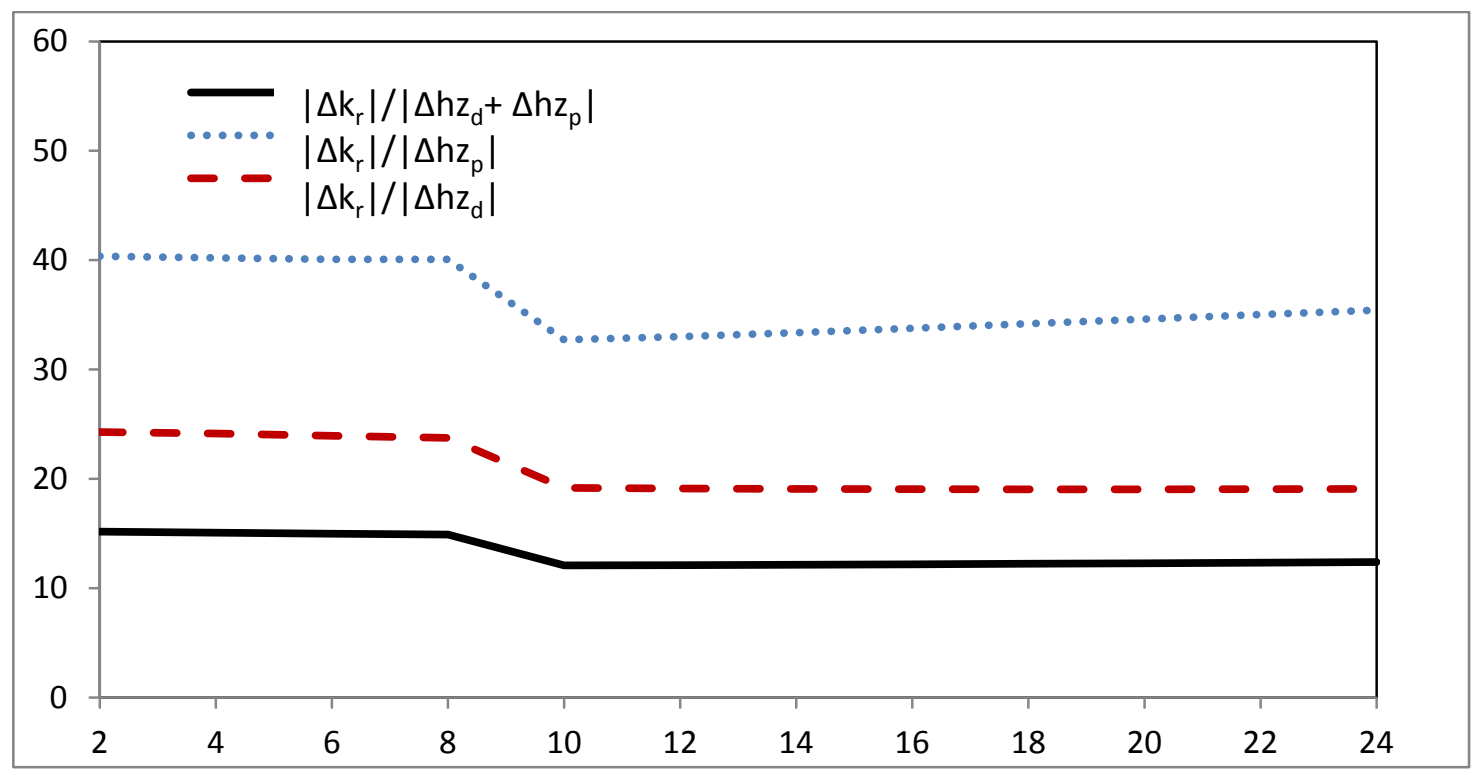

Figure 5. Effects of changing $\varepsilon_{3}$ on $\frac{\left|\Delta k_{r}\right|}{\left|\Delta h z_{d}\right|}, \frac{\left|\Delta k_{r}\right|}{\left|\Delta h z_{p}\right|}$, and $\frac{\left|\Delta k_{r}\right|}{\left|\Delta h z_{d}+\Delta h z_{p}\right|}$ 
To study the effects of lead time variation on the cost of SC members, a set of experiments is carried out. Figures 6, 7, and 8 show the retailer, distributor, and producer costs by changing $\varepsilon_{2}$, respectively. Each figure demonstrates the comparison of one SC member's cost under decentralized, centralized, and coordinated models.

Based on Figure 6, rising $\varepsilon_{2}$ may increase the probability of lead time aggregation between the distributor and retailer; therefore, the central decision maker may change the distributor decision variables to reduce the probability of lead time aggregation. Therefore, as shown in Figure 6, under centralized decision making, the retailer shortage cost is reduced. However, under coordinated decision making, by sharing some savings with upstream members, the retailer guarantees the participation of upstream members in coordinated decision making.

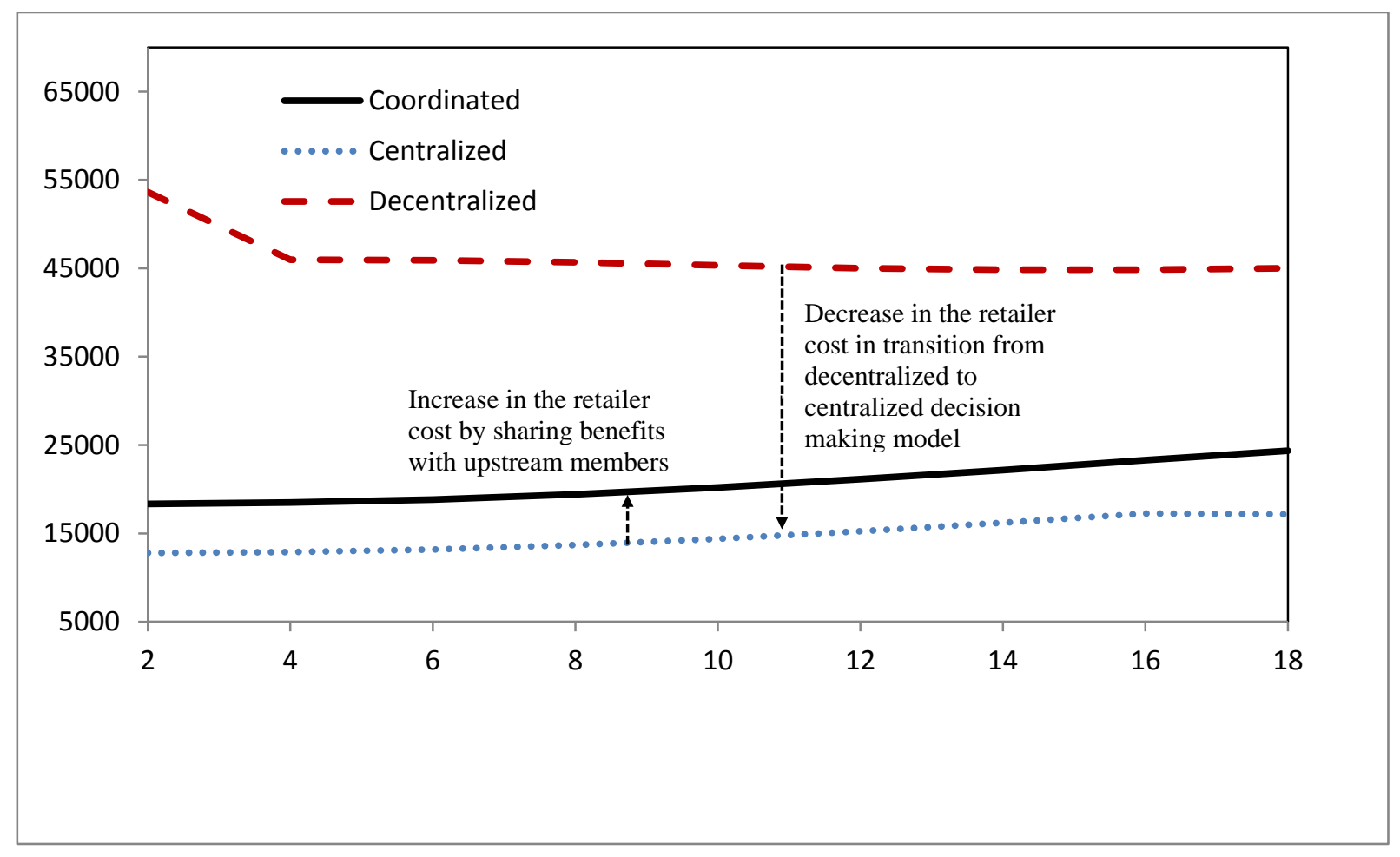

Figure 6. Effects of increasing $\varepsilon_{2}$ on the retailer costs in decentralized, centralized, and coordinated decision making models

Figure 7 illustrates the distributor cost in three decision making models by increasing the distributor lead time variance. As expected, the central decision maker advises for higher values of $n$ and $\varphi$. As a result, the distributor cost increases under centralized decision making. However, the proposed incentive scheme pulls down the distributor cost at a lower level than decentralized decision making and, therefore, the distributor participation is guaranteed. 


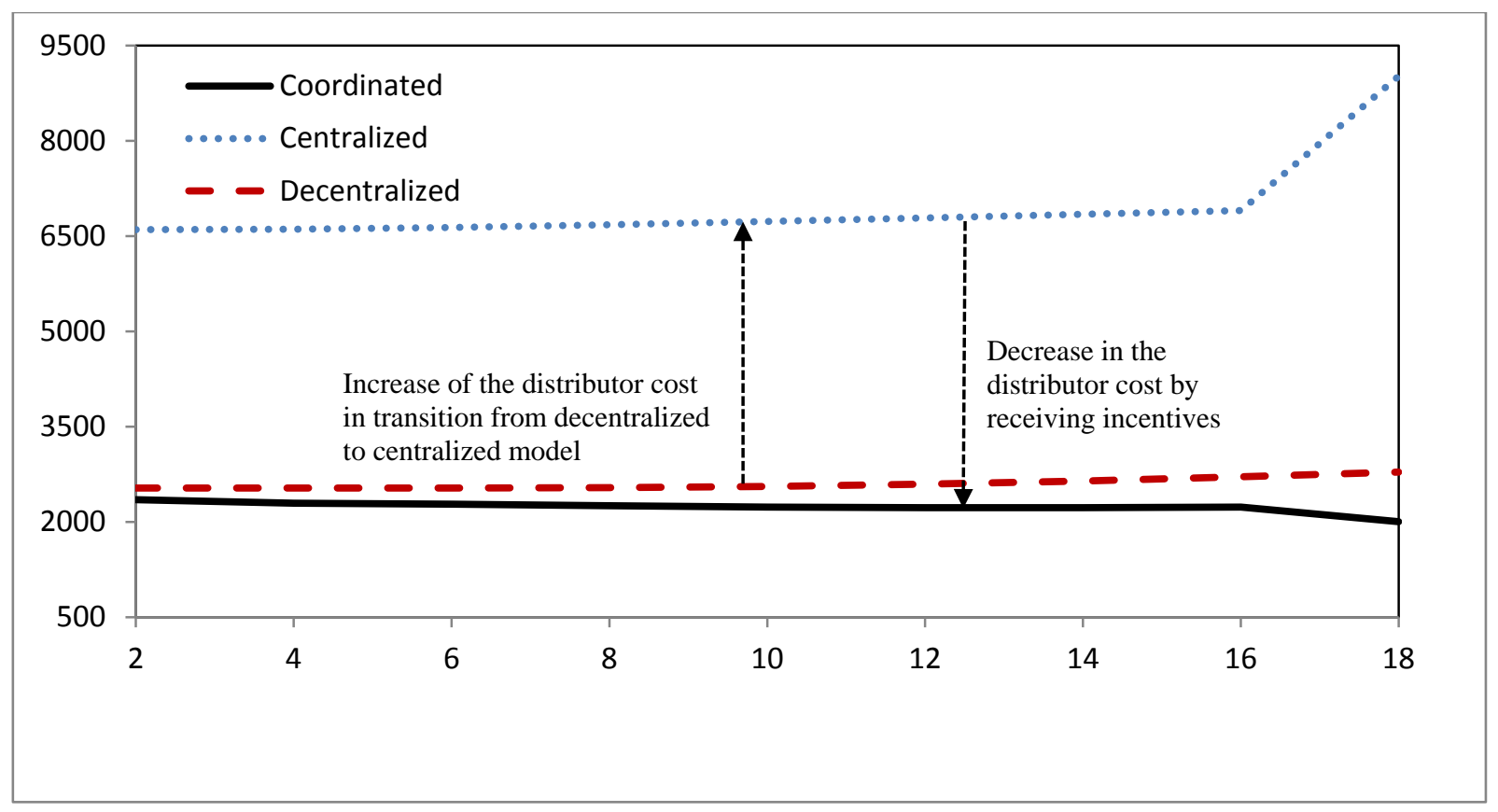

Figure 7. Effects of increasing $\varepsilon_{2}$ on the distributor costs in decentralized, centralized, and coordinated decision making models

Figure 8 also shows a similar situation for the producer. Accordingly, the proposed incentive scheme is capable of reducing the producer cost at a lower level than the decentralized model and, therefore, the producer has enough incentive to participate in the coordination model.

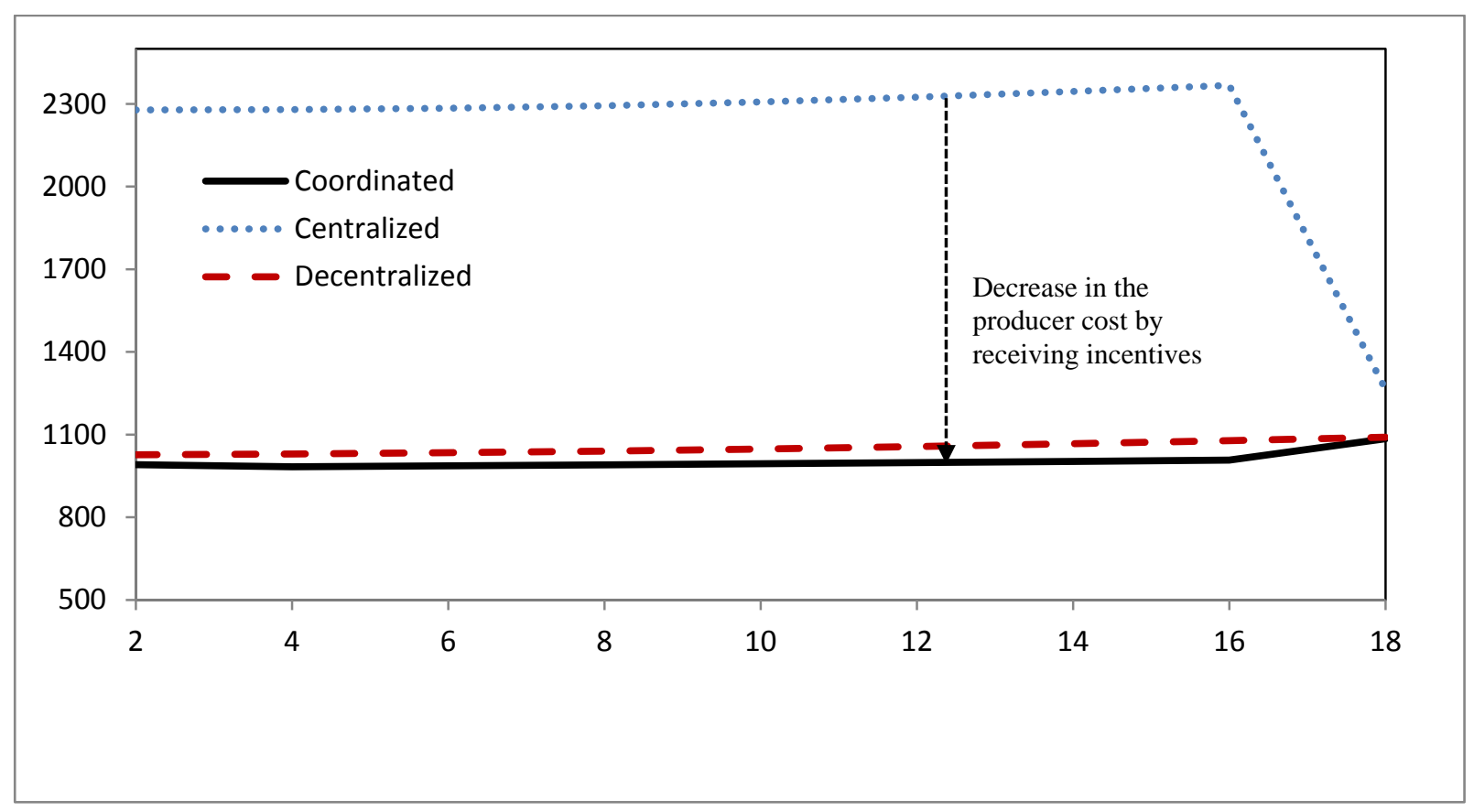

Figure8. Effects of increasing $\varepsilon_{2}$ on the producer costs in decentralized, centralized, and coordinated decision making models 


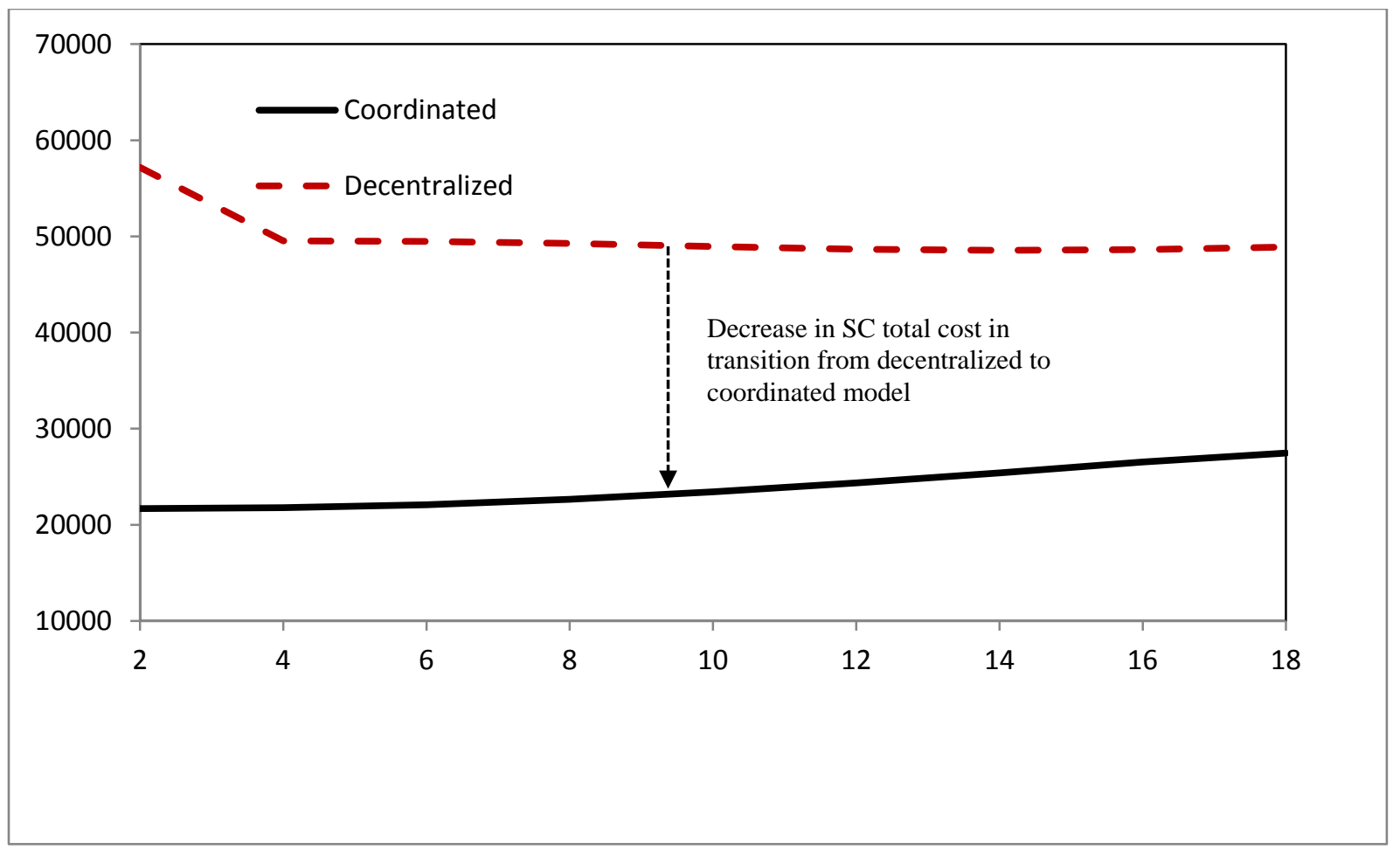

Figure 9. Effects of increasing $\varepsilon_{2}$ on the SC costs in decentralized and coordinated decision making models

Finally, Figure 9 shows the significant role of the proposed coordination mechanism in reducing the overall costs of SC. From Figure 9, one can conclude that SC total costs will be significantly reduced from decentralized to coordinated decision making model.

Although the investigated hypothetical test problems illustrate the performance of the proposed model under various conditions, to verify the applicability of the proposed model in the real business environment, a case study is also explored. In this study, an electronics-products import logistics system is investigated. The investigated logistics system is a two-layered distribution system: (1) one distribution center and (2) a local warehouse. In this study, we examine a distribution center which receives products in large batches from the port, one local distributor, and a network of brand outlets that are connected to the local distributor. All the brand outlets in the studied area are served by the investigated local warehouse. A specific electronics device with an approximately stable demand rate is studied. Replenishment sizes of both the distribution center and local warehouse are an integer multiple of the downstream's order quantity. Although the downstream lead time is approximately fixed, lead time between the distribution center and local warehouse could not be assumed deterministic because of the relatively long distance. The distribution center also suffers from stochastic lead times for replenishing its warehouse due to uncertainty in maritime transportation and also custom formalities. The case parameters are $D=30000$ (units/year), $Q=1250, \quad h_{r}=6$ (\$/item/year), $\quad h_{d}=4.5$ (\$/item/year), $\quad h_{p}=2$ (\$/item/year), $A_{r}=125$ (\$/order), $A_{d}=200$ (\$/order), $A_{p}=220$ (\$/order), $B_{r}=3$ (\$/item), $L_{r}=3$ (day), $\lambda_{2}=22$ (day), $\lambda_{3}=45$ (day), $\varepsilon_{2}=5$ (day), and $\varepsilon_{3}=12$ (day); $a$ and $b$ are unlimited, but to run the algorithms, 
$a=1$ (year) and $b=2$ (year) are considered large values. Parameters for the investigated case are estimated based on historical data and also expert estimations. In addition, to ensure confidentiality, the reported data are scaled. In the current state, local warehouse is replenished when there is no batch in its stock (i.e. $\varphi=1$ ) with $n=3$, while distribution center is replenished when there is only one batch to be shipped (i.e. $\tau=2$ ) with $p=2$. Estimated total cost for the current system is $T C_{s c}=37388.14$. The proposed model advises for $n=2, \varphi=2, p=2$, and $\tau=2$. Estimated total cost of supply chain under the proposed model would be $T C_{s c}=23866.48$. The proposed model, in this case, significantly decreases shortage cost at the retailer level. However, our investigations revealed that the current system does not appear so bad for managers due to the intangible nature of shortage costs at the retailer level. Therefore, the adoption of the proposed model depends on the raising awareness of managers about direct and indirect costs of shortages.

\subsection{Managerial insights}

Managerial insights from this study can be summarized as follows:

(1) From the general point of view, supply uncertainty or unreliable supply system may cause significant expenses for the downstream in a supply chain system. This study could help managers have a better understanding about the imposed costs on the downstream side and know how to cope with it.

(1) The proposed model can help managers recognize the critical role of lead time and effects of lead time uncertainties which can lead to an unpredictable long lead time for SC downstream members. Managers can obtain significant savings by optimizing the decisions involved to avoid shortages and grow the company's competitive capabilities.

(2) The proposed model can attract the attention of managers in this respect that by a limited change in upstream replenishment policies, it could be possible to reduce downstream costs significantly.

(3) More technically, this work could help managers manage their business when SC is facing long and unreliable lead times; in such cases, there is a risk for lead time aggregation. In the case of lead time aggregation, applying a semi-shaper strategy, like the one applied in this study, may cause great savings for all the SC members if properly adopted. In this case, the semi-shaper strategy means that the upstream members lessen the risk of lead time aggregation for the downstream by changing their replenishment policy.

\section{Conclusions}

Long and stochastic lead times may disrupt the SC flow of material and cause deficiencies such as dropping service level, increased shortages, loss of customers, and so on. In this paper, a three-echelon supply chain model consisting of one producer, one distributor, and one retailer under stochastic lead times for the upstream members is developed. Each SC member replenishes its stock based on a continuous inventory review process. In some replenishment cycles, upstream members are out of stock and two or three SC members might need to replenish 
their stock. In such cycles, lead time aggregation phenomenon would occur if the upstream lead time exceeds the time of issuing and order by downstream, which might lead to a considerable increase in shortages. In this paper, lead time aggregation in a three-echelon SC is investigated by modeling SC decision structure under two different policies: (1) decentralized decision making and (2) centralized decision making. It is revealed that centralized decision making leads to a substantial improvement in the whole SC costs by globally optimizing upstream replenishment decisions. However, centralized decision making often leads to higher costs for upstream members. To guarantee more profitability for all the members, an incentive scheme is proposed which could entice upstream members to optimize their replenishment decisions from the whole SC viewpoint.

The contribution of this paper can be mentioned from two perspectives: first, in terms of mathematical model, structure, and concept of lead time aggregation in the presence of unreliable supply system. Second, in terms of using a strategy to deal with uncertainties in a way that downstream is not restricted to use an adapter strategy (e.g. keeping more safety stock). Using adapter strategies confronting uncertainties is common in most of the previous studies; instead, in this study, a semi-shaper strategy is used (i.e. changing length of lead time aggregation by controlling upstream replenishment strategy). Numerical experiments illustrate the effectiveness of the joint decision making in the investigated SC. In addition, based on the sensitivity analyses, one can conclude that the proposed incentive scheme is capable of achieving channel coordination. The current model can be extended to network structures, instead of serially connected SC using a simulation study while both demand and lead time are stochastic. Applying the lead time aggregation phenomenon in transshipment for multi-location systems may also create useful results and further insights. Further, enhancing the proposed incentive scheme for sharing the earned profit may be an appropriate area for future works.

\section{Appendix: Details of calculating the distributor inventory holding cost under lead time aggregation}

The expected annual inventory holding cost is simply the product of the area under the inventory curve multiplied by the yearly rate of holding cost per item.

If lead time aggregation does not occur, then the area under the inventory curve of the distributor in a year is equal to (see hatched area in Figure 10):

$$
\frac{D}{n Q}\left((n-1) Q \frac{Q}{D}+(n-2) Q \frac{Q}{D}+\cdots+Q \frac{Q}{D}\right)=\frac{D}{n Q} \frac{(n-1) n}{2} Q \frac{Q}{D}=\frac{(n-1) Q}{2}
$$




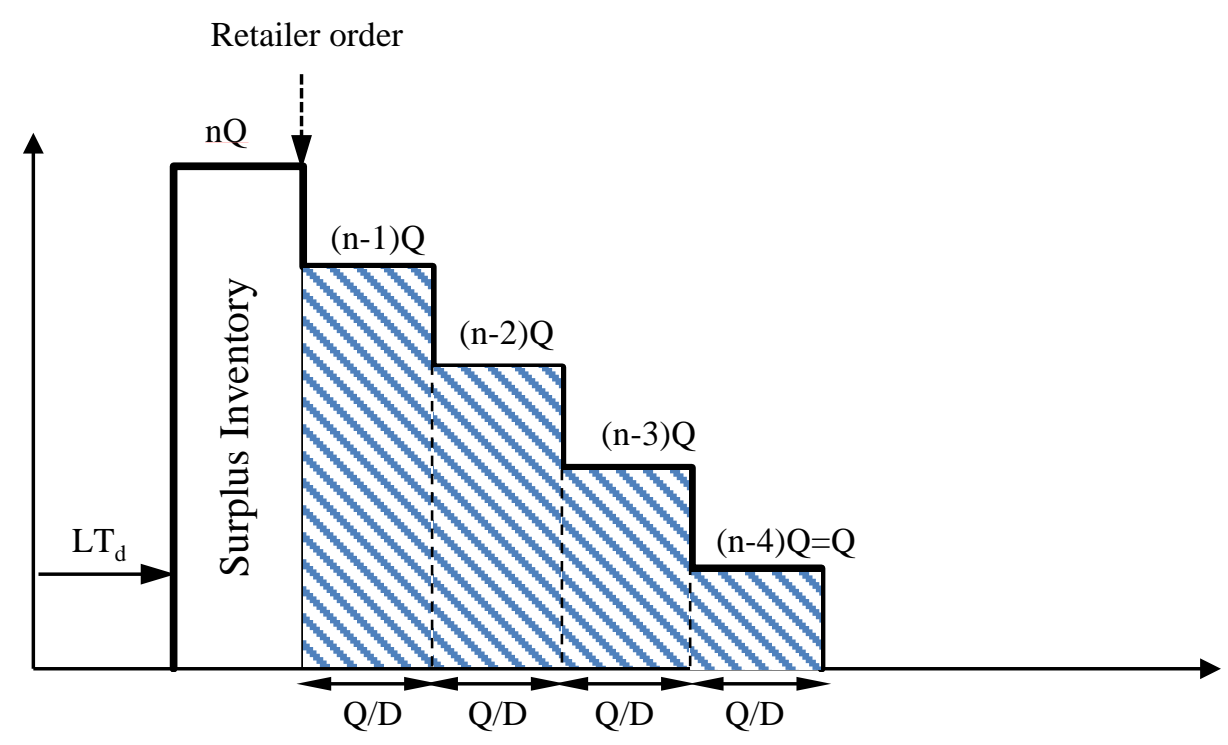

Figure 10. Area under the inventory curve of the distributor when lead time aggregation does not occur (for $n=5$ )

Note that we exclude expected surplus inventory in the case of short distributor's lead time from Equation (20). In the case of aggregating lead times of the distributor and retailer, Equation (20) is no longer valid. In such cases, the distributor ships all the delayed orders of the retailer at once immediately after receiving a batch from the producer. Therefore, the distributor inventory holding cost in the case of lead time aggregation is less than $\frac{(n-1) Q}{2}$. Figure 11 shows an example for the area under the inventory curve of the distributor when lead time aggregation occurs.

According to Figure 11, to calculate the inventory holding cost of the distributor, it is enough to detract Area I and Area II from the distributor replenishment cycle. 


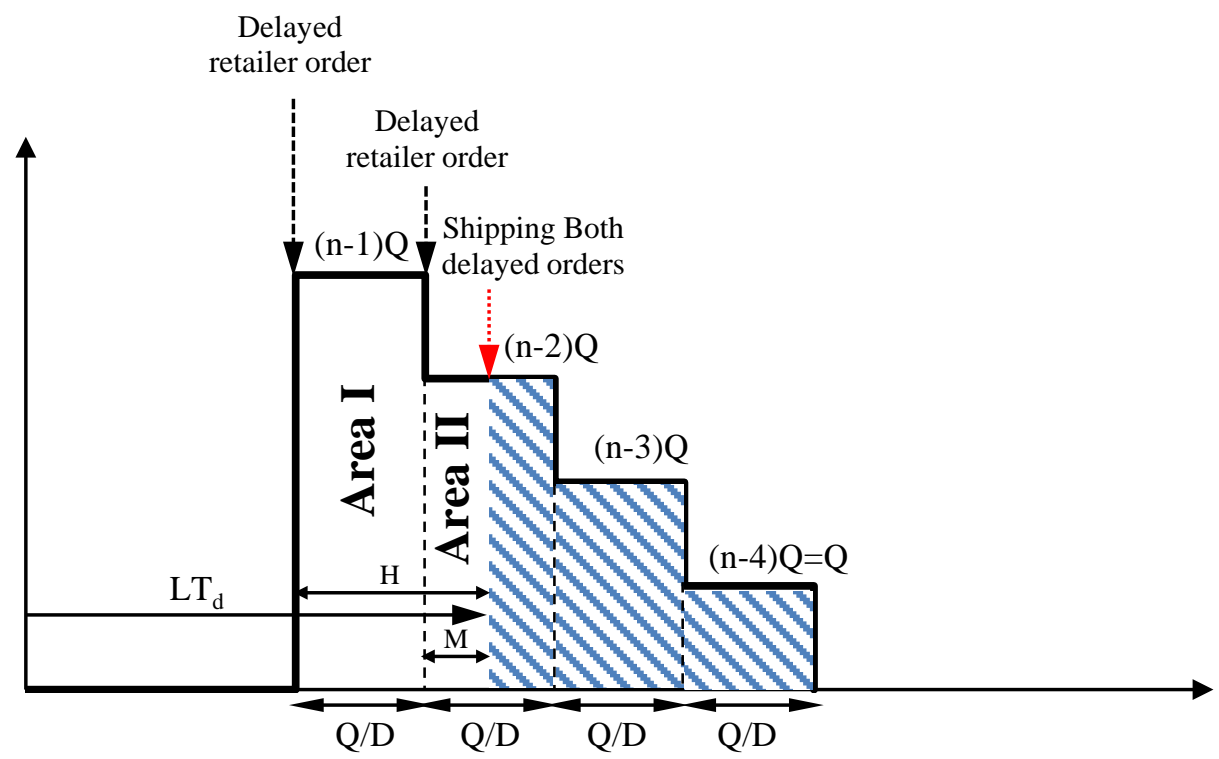

Figure 11. Areas under the inventory curve of the distributor when lead time aggregation occurs (for $\mathrm{n}=5$ )

Depending on the length of the distributor lead time, several retailer orders may be delayed and, finally, the distributor ships all at once. Area I in Figure 11 represents all the delayed retailer orders which should be shipped together. Area I in Figure 11 can be calculated as follows:

Area $1=\left(\sum_{i=1}^{\min }\left(\left[\frac{\int_{0}^{\infty}\left(Y-\varphi W_{r}\right) f\left(V_{r_{-}}\right) d V_{r_{-}} d}{\frac{Q}{D}}\right], n-1\right){ }_{(n-i) Q} \frac{Q}{D}\right)$

The upper bound of summation in Equation (21) indicates the number of complete steps in Area I. In $\frac{\int_{0}^{\infty}\left(Y-\varphi W_{r}\right) f\left(V_{r_{-} d}\right) d V_{r_{-}} d}{\frac{Q}{D}}$, the numerator denotes the duration of aggregation period (i.e. $H$ in Figure 11), while the denominator denotes the retailer replenishment cycle. Integer part of the above fraction represents the number of complete steps that should be detracted from the distributor replenishment cycle. Note that since there is $(n-1)$ complete steps in each distributor replenishment cycle, the upper bound of summation could not be greater than (n-1). In Figure 11, the upper bound of summation is equal to 1 .

To calculate Area II, at first, we calculate $M$ as follows:

$M=\left(\int_{0}^{\infty}\left(Y-\varphi W_{r}\right) f\left(V_{r_{-} d}\right) d V_{r_{-} d}\right)-\frac{Q}{D}\left\lfloor\frac{\int_{0}^{\infty}\left(Y-\varphi W_{r}\right) f\left(V_{r_{-} d}\right) d V_{r_{-} d}}{\frac{Q}{D}}\right\rfloor$ 
where the first term denotes duration of aggregation period (i.e. $H$ in Figure 11) and second term is the length of complete steps that should be detracted. Note that the length of each complete step is $\frac{Q}{D}$.

And the height of Area II is calculated by:

$$
Q\left((n-1)-\min \left(\left\lfloor\frac{\int_{0}^{\infty}\left(Y-\varphi W_{r}\right) f\left(V_{r_{-} d}\right) d V_{r_{-} d}}{\frac{Q}{D}}\right\rfloor, n-1\right)\right)
$$

In Figure 11, the height of Area II using Equation (23) is calculated as (n-2)Q.

Simply, Area II can be calculated as the product of Equation (23) and $M$.

We can calculate the hatched area in Figure 11 as follows:

Hatched Area $=\left[\left((n-1) Q \frac{Q}{D}+(n-2) Q \frac{Q}{D}+\cdots+Q \frac{Q}{D}\right)-\right.$ Area $I-$ Area $\left.I I\right]$

To obtain a relation for the expected inventory holding cost per year under lead time aggregation, we can write:

$E h_{d}=h_{d} \cdot \frac{D}{n Q}[\max \{$ Hatched Area, 0$\}]$

Equation (7) is the expanded form of Equation (25). Calculation for the producer's expected inventory holding cost per year under lead time aggregation (i.e. Equation 9) is also similar.

\section{References}

Arkan, A., Hejazi, SR., 2012. Coordinating orders in a two echelon supply chain with controllable lead time and ordering cost using the credit period.Computers\& Industrial Engineering. 62(1), 56-69.

Arshinder, Kanda A., Deshnukh SG. Supply chain coordination: perspectives, empirical studies and research directions. International Journal of Production Economics (2008); 115, 316-335.

Ben-Daya, M., Hariga, M., 2004.Integrated single vender single buyer model with stochastic demand and variable lead time. International Journal of Production Economics. 92(1), 75-80.

Bischak, D., Robb, D., Silver, E.A., Blackburn, J.D., 2014. Analysis and management of periodic review, order-up-to-level inventory systems with order crossover.ProductionandOperations Management. 23(5), 762-772.

Blackburn, J., 2012. Valuing time in supply chains: establishing limits of time-based competition.Journal of Operations Management. 30(5), 396-405.

Fang, X., Zhang, C., Robb, DJ., Blackburn, JD., 2013. Decision support for lead time and demand variability reduction.Omega. 41(2), 390-396.

Govindan, K., Popiuc, MN.,Diabat, A., 2013. Overview of coordination contracts within forward and reverse supply chains.Journal of Cleaner Production. 47, 319-334. 
Gupta, A., Maranas, C.D., 2003. Managing demand uncertainty in supply chain planning. Computers and Chemical Engineering. (27), 1219-1227

Gong, Y., Yucesan, E., 2012. Stochastic optimization for transshipment problems with positive replenishment lead times. International Journal of Production Economics. 135, 61-72.

Heydari, J., 2014a. Coordinating supplier's reorder point: A coordination mechanism for supply chains with long supplier lead time.Computers\& Operations Research. 48, 89-101.

Heydari, J., 2014b. Lead time variation control using reliable shipment equipment: An incentive scheme for supply chain coordination. Transportation Research Part E: Logistics and Transportation Review. 63, 44-58.

Heydari, J., Kazemzadeh, RB.,Chaharsooghi, SK., 2009. A study of lead time variation impact on supply chain performance.International Journal of Advanced Manufacturing Technology. 40, 1206-1215.

Hoque, MA., 2013a. A manufacturer-buyer integrated inventory model with stochastic lead times for delivering equal and/or unequal sized batches of a lot.Computers\& Operations Research. 40(11), 2740-2751.

Hoque, MA., 2013b. A vender-buyer integrated production-inventory model with normal distribution of lead time.International Journal of Production Economics. 144(2), 409-417.

Hsu, SL., Lee, CC., 2009. Replenishment and lead time decisions in manufacturer-retailer chains. Transportation Research Part E: Logistics and Transportation Review. 45(3), 398-408.

Kathmandu Post, 2014. Nepal's first privately owned English broadsheet daily, available online at: http://kathmandupost.ekantipur.com/news/2014-09-03/footwear-industry-hit-by-raw-materialshortage.html

Kim, T., Glock, CH., 2013. A multi-stage joint economic lot size model with lead time penalty costs. Computer \& Industrial Engineering. 66(1), 133-146.

Lee, SD., Fu, YC., 2014. Joint production and delivery lot sizing for a make-to-order producer-buyer supply chain with transportation cost. Transportation Research Part E:Logistics and Transportation Review. 66, 23-35.

Li, Y., Xu, X., Ye, F., 2011. Supply chain coordination model with controllable lead time and service level constraint. Computer \& Industrial Engineering. 61(3), 858-864.

Louly, MA.,Dolgui, A., 2013. Optimal MRP parameters for a single item inventory with random replenishment lead time, POQ policy and service level constraint.International Journal of Production Economics . 143(1), 35-40.

Mason, SJ., Ribera, PM., Farris, JA., Krik, RG., 2003. Integrating the warehousing and transportation functions of the supply chain. Transportation Research Part E: Logistics and Transportation Review. 39(2), 141-159.

Narus, J., Anderson, J.C. 1996. Rethinking Distribution: Adaptive Channels. Harvard Business Review. July-August, 112-120.

Noblesse, Ann M., Boute, Robert N., Lambrecht, Marc R., Van Houdt, Benny., 2014.Lot sizing and lead time decision in production/inventory systems.International Journal of Production Economics. 155, 351-360.

Pan, JC., Hsiao, YC., 2001. Inventory models with backorders discounts and variable lead time. International Journal of System Science. 32, 925-929.

Pan, JC., Hsiao, YC., 2005. Integrated inventory models with controllable lead time and backorder discount consolidations. International Journal of Production Economics.93-94, 387-397. 
Pan, JC., Yang, JS., 2002. A study of an integrated inventory with controllable lead time.International Journal of Production Research. 40(5), 1263-1273.

Priyan, S., Uthayakumar, R., 2015. Continuous review inventory model with controllable lead time, lost sales rate and order processing cost when the received quantity is uncertain. Journal of manufacturing systems. 34, 23-33.

Rossi, R., Tarim, SA.,Hnich, B., Prestwich, S., 2010. Computing the non-stationary replenishment cycle inventory policy under stochastic supplier lead-times.International Journal of Production Economics. 127(1), 180-189.

Roy, A., Sana, SS., Chaudhuri, K., 2012. Optimal replenishment order for uncertain demand in three layer supply chain.EconomicModelling.29(6), 2274-2282.

Sajadieh, MS., Jokar, MRA.,Modarres, M., 2009. Developing a coordinated vendor-buyer model in twostage supply chains with stochastic lead times.Computers\& Operations Research.36(8), 2484-2489.

Sarker, BR., Coates, ER., 1997. Manufacturing setup cost reduction under variable lead times and finite opportunities for investment.International Journal of Production Economics. 49(3), 237-247.

Sarmah, SP., Acharya, D., Goyal, SK., 2006. Buyer vendor coordination models in supply chain management. European Journal of Operational Research. 175(1), 1-15.

Simchi-Levi, D., Kaminsky, P., Simchi-Levi, E., 2000. Designing and managing the supply chain concepts, strategies, and case studies. Mc Graw Hill.

Simchi-Levi, D., Kaminsky, p., Simchi-Levi, E., 2004. Managing the supply chain, the definitive guide for business professional. Mc Graw Hill.

Tarantilis, CD., 2008. Topics in real time supply chain management. Computers \&Operations Research. 35(11), 3393-3396. 